\title{
ZnO on rice husk: a sustainable photocatalyst for urban air purification
}

Adrián Pastor, José Balbuena, Manuel Cruz-Yusta, Ivana Pavlovic and Luis Sánchez*

Departamento de Química Inorgánica, Instituto Universitario de Investigación en Química Fina y Nanoquímica IUIQFN, Universidad de Córdoba, Campus de Rabanales, E-14071 Córdoba, España.

* Corresponding Author:

- Prof. Luis Sánchez

ORCID ID: 0000-0002-0194-1908

Departamento de Química Inorgánica, Instituto Universitario de Investigación en Química Fina y Nanoquímica IUIQFN, Universidad de Córdoba, Campus de Rabanales, E-14071 Córdoba, España.

E-mail: luis-sanchez@uco.es

Tel: +00-34-957-218634 


\section{Abstract}

A cost-effective and sustainable De-NOx photocatalyst is prepared using zinc acetate and rice husk. $\mathrm{ZnO} @ \mathrm{SiO}_{2}$ samples are obtained from the calcination of a homogenised precursor mixture at $600{ }^{\circ} \mathrm{C}$. $\mathrm{ZnO}$ nanoparticles $(70-180 \mathrm{~nm})$ grow aggregated in spheres and well dispersed $\left(40-53 \mathrm{~m}^{2} \mathrm{~g}^{-1}\right.$ surface area) covering the silicon skeleton. The corresponding band gap for $\mathrm{ZnO} @ \mathrm{SiO}_{2}$ photocatalysts was estimated at $3.1-3.2 \mathrm{eV}$. When the samples are irradiated by sunlight in a nitrogen oxide atmosphere the $\mathrm{NO} \rightarrow \mathrm{HNO}_{2} \rightarrow \mathrm{NO}_{2} \rightarrow \mathrm{NO}_{3}^{-}$photochemical oxidation takes place. In comparison to unsupported $\mathrm{ZnO}$ and $\mathrm{TiO}_{2}-\mathrm{P} 25, \mathrm{ZnO} @ \mathrm{SiO}_{2}$ samples exhibit high $\mathrm{NO}_{\mathrm{x}}$ removal values $(70 \%)$ and outstanding selectivity (>90\%), the latter related to the sensitivity of zinc oxide towards $\mathrm{NO}_{2}$ gas. This new photocatalyst is easily recyclable and reusable.

\section{$\underline{\text { Keywords }}$}

Zinc oxide, Photocatalyst, Nitrogen oxides 


\section{Introduction}

Semiconductor (SC) photocatalysts have been widely studied as suitable materials for environmental remediation. A multitude of compounds, based mainly on $\mathrm{TiO}_{2}, \mathrm{ZnO}, \mathrm{CdS}, \mathrm{Fe}_{2} \mathrm{O}_{3}$ and $\mathrm{WO}_{3}$, were reported for the photocatalytic degradation of a variety of water, air and solid pollutants[1, 2]. In the recent years, an increasing interest has arisen in the study of the photochemical oxidation (PCO) of nitrogen oxide gases as a sustainable tool to combat urban air pollution[3].

Because of their toxicity, the presence of nitrogen oxides, commonly referred as $\mathrm{NO}_{\mathrm{x}}-$ nitric oxide (NO) and nitrogen dioxide $\left(\mathrm{NO}_{2}\right)^{-}$, in the urban environment is a high risk for human health[4]. Thus, environmental agencies in the USA and European Community limit the hourly $\mathrm{NO}_{\mathrm{x}}$ air concentration to $0.1 \mathrm{ppm}$ and $0.2 \mathrm{ppm}$, respectively. However, these limits are difficult to be attained because the $\mathrm{NO}_{\mathrm{x}}$ emissions rates from older vehicles worsen as time goes on[5]. In fact, nowadays higher $\mathrm{NO}_{x}$ levels are measured in very populated cities all over the world and thousands of early deaths worldwide are associated with these $\mathrm{NO}_{\mathrm{x}}$ emissions $[6,7]$. Today's research works have demonstrated the potential applicability of semiconductors in directly removing large amounts of $\mathrm{NO}_{\mathrm{x}}$ gases (De- $\mathrm{NO}_{\mathrm{x}}$ action) from the urban centres in our cities. In fact, at present, depolluting building materials, using $\mathrm{TiO}_{2}$ as a photocatalytic additive, are integrated in some advanced buildings in an attempt to achieve effective $\mathrm{NO}_{\mathrm{x}}$ de-pollution in urban areas[8]. In this sense, many researchers pay attention to the preparation of modified titania with enhanced $\mathrm{De}-\mathrm{NO}_{\mathrm{x}}$ photocatalytic performance[9-13].

However, it's necessary to point out that $\mathrm{TiO}_{2}$ has just been proposed to be classified as possibly causing cancer when inhaled[14]. This could limit some of its applications and, therefore, a rapid advance in the study and development of new De-NOx photocatalysts is desired. $\mathrm{g}-\mathrm{C}_{3} \mathrm{~N}_{4}, \mathrm{~N}-(\mathrm{BiO})_{2} \mathrm{CO}_{3}$, $\mathrm{BiOBr}, \mathrm{Bi} / \mathrm{ZnWO}_{4}$, or $\mathrm{Ni}-\mathrm{Bi}_{2} \mathrm{O}_{3}$ among others, were reported as alternative materials towards the photochemical NO abatement[15-20]. In this work we study the De- $\mathrm{NO}_{x}$ ability of $\mathrm{ZnO}$, which is not considered to be a threat to consumers health[21]. Even though $\mathrm{ZnO}$ is a preferred photocatalyst because of its high photosensitivity, mechanical-thermal stability and tuneable morphology, only a few studies have been recently reported for this specific environmental application. Some of them are 
devoted to enhancing titanium dioxide $\mathrm{De}-\mathrm{NO}_{\mathrm{x}}$ efficiency through the preparation of $\mathrm{TiO}_{2} / \mathrm{ZnO}$ composites[22, 23]. In the case of a pure $\mathrm{ZnO}$ photocatalyst, whose preparation proceeded by using amine derivatives or ionic liquids, the NO conversion photo-efficiency was equal to or lower than 50 $\%[24-28]$. On the other hand, the preparation of $\mathrm{ZnO}$ spheres by a carbon template via the one-step process is highly interesting, the resulting compound showing the highest photocatalytic activity[28]. Herein we propose a very simple procedure that allows us to obtain a $\mathrm{ZnO}$ efficient photocatalyst by using rice husk ash (RHA) as a support, a strategy successfully employed in the preparation of metals and metal oxides (photo)catalysts[29-32]. Rice husk (RH) is an agricultural waste product, the ash of which contains about $92-95 \%$ silica $\left(\mathrm{SiO}_{2}\right)[29]$, and when used to synthesize silica nanoparticles, offers additional advantages, including greener raw materials, lower costs, and higher sustainability[30]. The

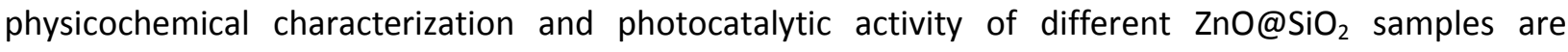
presented. Remarkably, as the main novelty, $\mathrm{De}-\mathrm{NO}_{\mathrm{x}} \mathrm{ZnO}$ based photocatalysts are prepared using a cost-effective and large-scale synthetic procedure and exhibiting the highest NO photo-chemical conversion efficiency and selectivity values reported. Due to the high selectivity values found, the use of photocatalysis proves to be sustainable as a NO abatement process.

\section{Materials and methods}

\subsection{Preparation of ZnO supported photocatalyst}

The complete characterization of RHA support is provided in Supplementary Information (SI; Figures S1 - S4 and Table S1). With the aim of obtaining a cost-effective and large-scale synthesis procedure in mind, the methodology used for the preparation of a photocatalyst was as simple as possible. Zinc acetate is a very cheap salt that is successfully used in the synthesis of ZnO-based materials[33]. $\mathrm{Zn}(\mathrm{OAc})_{2} \cdot 2 \mathrm{H}_{2} \mathrm{O}(99,0 \%$, Sigma-Aldrich) and $\mathrm{RH}$ were used as precursor components, in the 0.65 weight ratio. This ratio was selected following that previously reported as optimum in the preparation of a catalyst on RHA as a support[34], focussing the attention of this preliminary work in the 
preparative methodology. Two methods were chosen in order to enhance the contact between the precursor components:

i) Liquid to solid deposition. $30.73 \mathrm{~g}$ of $\mathrm{Zn}(\mathrm{OAc})_{2} \cdot 2 \mathrm{H}_{2} \mathrm{O}$ was dissolved in $150 \mathrm{~mL}$ of milliQ water. Subsequently, $20 \mathrm{~g}$ of RH was added to the vessel. After $30 \mathrm{~min}$ of magnetic stirring, the paste was dried at $80{ }^{\circ} \mathrm{C}$ for 4 days. Later, the product was calcined at $600{ }^{\circ} \mathrm{C}$ for 2 and 4 hours. The photocatalyst samples obtained were denominated as dZn@RHA-2 and dZn@RHA-4, respectively.

ii) Mechanical milling. A mixture of $30.73 \mathrm{~g}$ of $\mathrm{Zn}(\mathrm{OAc})_{2} \cdot 2 \mathrm{H}_{2} \mathrm{O}$ and $20 \mathrm{~g}$ of $\mathrm{RH}$ was milled using a planetary mill (45 min, $300 \mathrm{rpm}$ ). The collected product was calcined at $600{ }^{\circ} \mathrm{C}$ for 2 and 4 hours. The photocatalyst samples obtained were denominated as mZn@RHA-2 and mZn@RHA-4, respectively.

\subsection{Sample characterization}

Energy Dispersive X-ray Fluorescence analysis (XRF) was done in a ZSX Primus IV (Rigaku) equipment. The carbon content elemental analysis was determined by using an Eurovector EA 3000 elemental instrument. Crystalline phases were identified by using X-ray diffraction (XRD). The XRD patterns were recorded in a Bruker D8 Discover A25 diffractometer. The crystal size of the samples was determined by means of the Scherrer equation. This equation was calculated with DIFFRACT.EVA V3.1 software. The morphology of the samples was examined by scanning electron microscopy (SEM). SEM images were obtained with a Jeol JMS-6400 microscope. Particle size distribution was estimated using a Visiolog 6.1 software. Nitrogen absorption isotherms were obtained at $77.4 \mathrm{~K}$ on an ASAP 2020 instrument from Micromeritics, from which the specific surface areas were calculated using the multipoint BrunauerEmmett-Teller (BET) and Barrett-Joyner-Halenda (BJH) methods. Diffuse reflectance (DR) spectra were recorded using a Varian Cary 1E spectrophotometer. Thermogravimetry (TGA) was carried out with a Mettler Toledo in air atmosphere (flow: $100 \mathrm{~mL} \mathrm{~min}{ }^{-1}$ ) from room temperature to $600{ }^{\circ} \mathrm{C}$ (heating rate of $\left.10^{\circ} \mathrm{C} \mathrm{min}^{-1}\right)$. 
Additional information is provided in SI.

\subsection{Photocatalytic activity tests}

The photocatalytic activity of the materials towards the oxidation of NO was studied using a protocol similar to the standardised test method developed for the characterisation of air-purification performance, ISO 22197-1 [35]. However, some of the specifications described in this standard were modified in order to obtain better performance with the samples of this study. Thus, the tests were carried out on a $50 \mathrm{~mm} \times 50 \mathrm{~mm}$ sample holder placed in a laminar flow reactor [35]. Artificial sunlight irradiation (Solarbox 3000e RH light irradiation box) was obtained with an Xe lamp with controlled irradiance ( 25 and $580 \mathrm{Wm}^{-2}$ for UV and visible, respectively). For each De-NO $\mathrm{x}$ test, $1.0 \mathrm{~g}$ of the sample supported on the sampler holder inside the reactor was used. As a pollutant, a mixture of air/NO was sent to the photoreactor with a NO concentration of $150 \mathrm{ppb}$ (obtained by mixing synthetic air and pure NO). This concentration was chosen because it is representative of NO concentrations found during intense photochemical pollution periods in urban environments [6], having already been successfully adopted in previous research works $[15,36,37]$. The gas mixture was supplied by using a flow rate of $0.30 \mathrm{~L} \mathrm{~min}^{-1}$ and fixing the relative humidity at $50 \pm 5 \%$. The measurement of the concentration of NO, $\mathrm{NO}_{\mathrm{x}}$ and $\mathrm{NO}_{2}$ gases was carried out using a chemiluminescence analyser (model Environnement AC32M). Each test was repeated three times to obtain average concentration values. The calculated standard deviations were $\pm 0.3 \mathrm{ppb}$ for $\mathrm{NO}$ concentration and $\pm 1.0 \mathrm{ppb}$ for $\mathrm{NO}_{2}$ and $\mathrm{NO}_{\mathrm{x}}$ concentrations. The photocatalytic efficiency was evaluated following the $\mathrm{NO}$ conversion (\%), $\mathrm{NO}_{2}$ released (\%) and $\mathrm{NO}_{\mathrm{x}}$ conversion (\%) parameters (defined in SI). 


\section{Results and discussion}

\subsection{Photocatalyst characterisation}

$\mathrm{ZnO@SiO}{ }_{2}$ supported photocatalysts were obtained after the calcination of the $\mathrm{Zn}(\mathrm{OAc})_{2} / \mathrm{RH}$ precursor mixtures. The chemical composition of samples is provided in Table S2. The XRD patterns obtained for the four samples are shown in Figure 1 . Only peaks ascribable to hkl reflections of hexagonal structure of $\mathrm{ZnO}$ (wurtzite) were detected. The diffraction peaks at $31.5^{\circ}, 34.2^{\circ}, 36.1^{\circ}, 47.3^{\circ}$, $56.4^{\circ}, 62.7^{\circ}, 66.1^{\circ}, 67.7^{\circ}$ and $68.9^{\circ}$ two theta degrees can be attributed to (100), (002), (101), (102), (110), (103), (200), (112) and (201) crystal planes, respectively[38]. Apart from its amorphous character, the negligible presence of the silica halo expected at $22^{\circ}$ (Fig S5)[39] would be indicative of good zinc oxide covering on the silica support. For comparison purposes, $\mathrm{ZnO}$ without the use of $\mathrm{RH}$ was also prepared using the same calcination procedure. The $\mathrm{ZnO}$ samples thus obtained after 2 and 4 hours of calcination were labelled as Zn-2 and Zn-4, respectively. Their corresponding XRD patterns also show the formation of pure zinc oxide. In the case of silica supported samples, the intensity of diffraction peaks is significantly lower than that observed for $\mathrm{Zn}-2$ and $\mathrm{Zn}-4$ samples. Thus, the smallest crystallite size

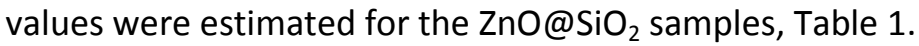

The SEM images for dZn@RHA samples, Figure 2, show ZnO particles growing dispersed on the cob-shaped skeleton, being aggregated in spheres of different sizes. The milling process breaks this skeleton but similar particle aggregation is observed for mZn@RHA samples, Figure 3 (a-d). In both cases, the wurtzite particle size is around 70-180 $\mathrm{nm}$ (Figure S6a). For the whole set of samples, the silica support (Supplementary Information) appears completely covered by ZnO particles, as expected from XRD patterns. The extended heating period of up to 4 hours had no significant influence on the morphology of the $\mathrm{ZnO}$ crystals. The silica skeleton acts as a support but also as a template influencing the growth of the wurtzite crystals. Thus, without the use of $\mathrm{RH}$, the $\mathrm{ZnO}$ is constituted by independent larger amorphous nanoparticles of 140-280 nm, Figure $3(\mathrm{e}, \mathrm{f})$ and Figure S6b. 
The differences observed in $\mathrm{ZnO}$ crystallite size and morphology, with and without the use of $\mathrm{RH}$, clearly reveal the influence of rice husk on the $\mathrm{ZnO}$ growth. This could be explained by assuming the following crystal growth mechanism. Since the RH decomposes at a lower temperature than the zinc acetate precursor (Figure S1), ZnO crystallizes once the amorphous silica is formed. By considering the appearance of the Zener pinning process[40], the growth of the first ZnO crystals must be restricted by the presence of silica as an inert phase, which is believed to result in tiny discrete particles located in the interface regions between the emergent $\mathrm{ZnO}$ nanocrystals. These reduce the radius of the crystallite surfaces, thus increasing the energy required for growth. This would explain the limited size of $\mathrm{ZnO}$ crystals and nanoparticles in Zn@RHA samples (Figure S6; Table 1).

Table 1. The surface analysis parameters and crystallite size for zinc oxide samples

\begin{tabular}{|c|c|c|c|c|c|c|c|}
\hline Sample & $\begin{array}{c}\text { BET } \\
\text { surface } \\
\text { area } \\
\left(\mathrm{m}^{2} \cdot \mathrm{g}^{-1}\right) \\
\end{array}$ & $\begin{array}{c}\mathrm{BJH}^{*} \\
\text { pore } \\
\text { volume } \\
\left(\mathrm{cm}^{3} \cdot \mathrm{g}^{-1}\right) \\
\end{array}$ & $\begin{array}{c}\text { BJH* }^{*} \\
\text { mesoporous } \\
\text { volume } \\
\left(\mathrm{cm}^{3} \cdot \mathrm{g}^{-1}\right) \\
\end{array}$ & $\begin{array}{c}\text { BJH* }^{*} \\
\text { average pore } \\
\text { diameter } \\
(\mathrm{nm}) \\
\end{array}$ & $\begin{array}{c}\text { BJH* }^{*} \\
\text { surface } \\
\text { area } \\
\left(\mathrm{m}^{2} \cdot \mathrm{g}^{-1}\right) \\
\end{array}$ & $\begin{array}{c}\text { BJH* } \\
\text { mesoporous } \\
\text { surface area } \\
\left(\mathrm{m}^{2} \cdot \mathrm{g}^{-1}\right) \\
\end{array}$ & $\begin{array}{c}\text { Crystallite } \\
\text { size } \\
(\mathrm{nm})\end{array}$ \\
\hline dZn@RHA-2 & 49,3 & 0,11 & 0,08 & 8,99 & 48,5 & 42,3 & 23,6 \\
\hline dZn@RHA-4 & 53,5 & 0,13 & 0,1 & 9,00 & 56,2 & 49,5 & 25,0 \\
\hline mZn@RHA-2 & 40,3 & 0,11 & 0,08 & 9,00 & 47,1 & 41,5 & 32,7 \\
\hline mZn@RHA-4 & 50,7 & 0,10 & 0,07 & 8,66 & 45,1 & 38,8 & 36,9 \\
\hline $\mathrm{Zn}-2$ & 4,5 & 0,01 & 0,01 & 17,15 & 3,3 & 2,5 & 62,0 \\
\hline$Z n-4$ & 2,8 & 0,01 & 0,01 & 21,02 & 1,8 & 1,4 & 72,1 \\
\hline
\end{tabular}

* Determined from the $\mathrm{N}_{2}$ desorption isotherm

Because of the derived dependence on the photocatalytic activity, the preparation of ZnO with a large surface area has been studied extensively [41]. The ZnO exhibits very complex and diversified morphologies, and the manipulation of a desirable structure for the rational tailoring of surface to volume ratios was largely reported. Thus, as way of example, large surface area ZnO photocatalysts were prepared such as spherical shape nanocrytals, flower-like, mesoporous, nanostar, nanofibers, tetrapods, nanorod arrays, porous nanopyramids, porous nanosheets, hollow spheres, 
nanotube arrays and porous films morphologies. Various preparative methods were employed such as capping agent, spray pyrolysis, the solution combustion route, the biotemplate-assisted approach, electrospinning, thermal evaporation, the solution-phase approach, the polyol solution route or chemical deposition [41]. Here we explore the influence of RH on the preparation of $\mathrm{ZnO}$ with increased surface area. Thus, in order to establish the surface area and porous structure of the photocatalysts, the corresponding $\mathrm{N}_{2}$ adsorption-desorption isotherms were measured.

In comparison with the bare RHA support (Figure S4), the pore structure changes considerably once $\mathrm{ZnO}$ growth covers silica support, Figure 4. The isotherms of $\mathrm{ZnO} @ \mathrm{SiO}_{2}$ composites exhibited almost the same shape, being similar to BET classification type II. These porous materials are constituted mainly by mesopores in a wide range of sizes (Figure 4 insets). Table 1 summarizes the main surface properties of the $\mathrm{ZnO@SiO} 2$ and $\mathrm{ZnO}$ samples. The pronounced hysteresis loop observed in the $0.45-0.95 \mathrm{P} / \mathrm{P}_{0}$ range for the RHA sample (Figure $\mathrm{S} 4$ ) is almost closed. These pores are progressively blocked and covered by the $\mathrm{ZnO}$ crystals on the surface, thus explaining the significant decrease of $\mathrm{N}_{2}$ adsorption on $\mathrm{ZnO} @ \mathrm{SiO}_{2}$, as observed for other metal oxides catalysts supported on RHA[42]. The new porous structure formed by wurtzite covering the silica skeleton exhibits a surface area of around 40 $53 \mathrm{~m}^{2} \mathrm{~g}^{-1}$, being larger for samples obtained after 4 hours of calcination. In spite of the loss of surface area found from RHA to $\mathrm{ZnO} @ \mathrm{SiO}_{2}$ samples, which was four times lower, the use of a silica skeleton as a support is of high interest. Thus, without the use of RHA the isotherms show a collapsed microstructure for samples Zn-2 and Zn-4, exhibiting negligible surface area values lower than $5 \mathrm{~m}^{2} \mathrm{~g}^{-1}$ (Figure 4; Table I). From the results commented above, the beneficial effect of RHA as a template, which allows smaller and well dispersed ZnO particles, can be concluded.

The optical properties of the six samples were studied by a UV-visible diffuse reflectance spectroscopy (Figure S7). The acquired diffuse reflectance spectra were converted to the Kubelka-Munk function, $\left[F\left(R_{\infty}\right) h v\right]^{2}$. The band gap energies of the samples are estimated from the tangent lines in the plots of the Kubelka-Munk function vs. the energy of exciting light, as shown in Figure 5. As expected, as $\mathrm{SiO}_{2}$ is as a good insulator material ( $8 \mathrm{eV}$; band gap energy) [43], significant changes were not 
observed for the composites. The estimated band-gap values were in line with those reported for pure $\mathrm{ZnO}[28,44,45]$. Depending on the morphology and particle size of the samples (Table 1 ), they ranged between 3.1 and $3.2 \mathrm{eV}$. As previously reported [38] a slight decrease in band-gap values was observed

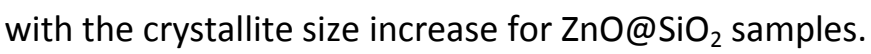

\subsection{De-NO photocatalytic tests}

The photochemical ability of $\mathrm{ZnO} @ \mathrm{SiO}_{2}$ samples to abate the atmospheric concentration of nitrogen oxides gases was studied. The photochemical De-NO process proved to be efficient when $\mathrm{NO}_{\mathrm{x}}$ gases were removed from the air through their complete oxidation to nitrite/nitrate $\left(\mathrm{NO}_{2}{ }^{-} / \mathrm{NO}_{3}{ }^{-}\right)$species. This is not a simple process as it involves several intermediate species[3, 46]. Briefly, it can be summarised as follow:

$$
\begin{aligned}
& \mathrm{SC}+h v \Rightarrow \mathrm{e}^{-}+\mathrm{h}^{+} \\
& \mathrm{H} \mathrm{O}^{+} \mathrm{h}^{+} \Rightarrow \mathrm{H}^{+}+\mathrm{OH} \bullet \\
& \mathrm{NO}+2 \mathrm{OH} \bullet \Rightarrow \mathrm{NO}_{2}+\mathrm{H}_{2} \mathrm{O} \\
& \mathrm{NO}_{2}+\mathrm{OH} \bullet \Rightarrow \mathrm{NO}_{3}^{-}+\mathrm{H}^{+} \\
& \mathrm{NO}^{+} \mathrm{NO}_{2}+\mathrm{H}_{2} \mathrm{O} \Rightarrow 2 \mathrm{HNO}_{2} \\
& \mathrm{O}_{2}+\mathrm{e}^{-} \Rightarrow \cdot \mathrm{O}_{2}^{-} \\
& \mathrm{NO}_{x}+\cdot \mathrm{O}_{2}^{-} \Rightarrow \mathrm{NO}_{3}^{-}
\end{aligned}
$$

Therefore, when sunlight shines on $\mathrm{ZnO}$ nanoparticles (semiconductor, SC) the electron in the valence band (VB) acquires the necessary energy to migrate to the conduction band (CB), (reaction 1). The pairs of mobile charges $\left(e^{-}\right.$and $\left.h^{+}\right)$that reach the surface of the semiconductor particles react with the adsorbed water and oxygen molecules $(2,6)$. Thus, the formation of reactive oxygen species (ROS) - as previously reported for $\mathrm{ZnO}$ systems $[25,26]-$ and the 
progressive oxidation of nitrogen oxide gases is initiated $(3,4,5,7)[24-26,28]$. During this process, the presence of the intermediate $\mathrm{NO}_{2}$ gas must be reduced as much as possible (3) because $\mathrm{NO}_{2}$ is far more dangerous than NO [47]. Figure 6 shows the evolution of the nitrogen oxide concentration profiles recorded for the $\mathrm{ZnO} @ \mathrm{SiO}_{2}$ samples as a function of light irradiation time. In the absence of light irradiation, in the first ten minutes of the test, the concentration of gases stayed constant confirming that neither NO gas adsorption nor any reaction on the $\mathrm{ZnO}$ particle surface occurred.

The photochemical oxidation (PCO) process began on the $\mathrm{ZnO}$ active sites once the lamp was switched on, as inferred from the sudden decrease observed for NO concentration. This PCO process was kept constant during the 30 min of light irradiation and stopped when the light was turned off, then the NO concentration returned to its initial value. Following this experiment, the decrease in NO concentration values measured during the light irradiation period was related to the amount of removed NO. For comparison purposes, the commercial Aeroxide ${ }^{\circledR} \mathrm{TiO}_{2} \mathrm{P}_{25}$ (Evonik) was also studied, a material broadly used worldwide as a reference in photocatalysis. In fact, this material is quite similar to the studied samples in reference to band-gap energy, crystal size and surface area (3.18 eV ; $\left.23-44 \mathrm{~nm} ; 48.6 \mathrm{~m}^{2} \mathrm{~g}^{-1}\right)$ [48].

As expected, the NO conversion value was related to the surface area exhibited by the samples, around $75 \%$ for $\mathrm{ZnO@} \mathrm{SiO}_{2}$ samples and $\mathrm{TiO}_{2} \mathrm{P} 25$, and decreasing around $50 \%$ for pure ZnO samples, Figure 6a and Figure 7. As previously mentioned, it is worth remarking on the subsequent appearance of the highly toxic $\mathrm{NO}_{2}$ gas whose amount differs between samples. As is known for other modified titania photocatalysts, and different benchmark $\mathrm{TiO}_{2}$ samples, the emission of $\mathrm{NO}_{2}$ increases continuously under light irradiation in the case of the $\mathrm{TiO}_{2}-\mathrm{P} 25$ sample, Figure $6 \mathrm{~b}[48]$. Thus, the highest slope observed for $\mathrm{TiO}_{2}-\mathrm{P} 25$ would indicate that the theoretical full oxidation of NO towards nitrites/nitrates lowers with the irradiation time, thus explaining the noticeably increased amount of $\mathrm{NO}_{2}$ molecules released during the experiment. This

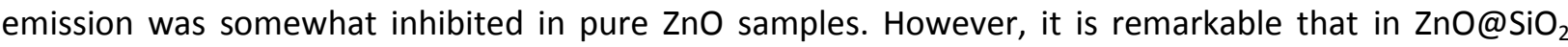


samples the amount of $\mathrm{NO}_{2}$ concentration measured is negligible. By considering a sustainable process, the photocatalytic De- $\mathrm{NO}_{x}$ process must address not only the highest $\mathrm{NO}$ conversion values, but also the aim of achieving the highest De-NO ${ }_{x}$ selectivity. The selectivity system parameter, $S$, expresses the ratio of degraded NO fully converted into harmless nitrite/nitrate rather than into toxic nitrogen dioxide, being determined according to the equation:

$$
S(\%)=\frac{\left([\mathrm{NOx}]_{\text {in }}-[\mathrm{NOx}]_{\text {out }}\right) /[\mathrm{NOx}]_{\text {in }}}{\left([\mathrm{NO}]_{\text {in }}-[\mathrm{NO}]_{\text {out }}\right) /[\mathrm{NO}]_{\text {in }}} \times 100
$$

Therefore, the highest $\mathrm{S}$ values mean the highest amount of nitrogen oxides removed from air. For a better comprehension of the results obtained, Figure 7 shows the conversion/emission nitrogen oxide values together with the photocatalytic $\mathrm{NO}_{\mathrm{x}}$ abatement selectivity $(S)$, in the case of $\mathrm{ZnO} @ \mathrm{SiO}_{2}$ and should be compared with those obtained for common photocatalysts: $\mathrm{ZnO}$ and $\mathrm{TiO}_{2}-\mathrm{P} 25$ samples. The outstanding results with S values above $90 \%$ measured for $\mathrm{ZnO} @ \mathrm{SiO}_{2}$ samples, allowed a high amount of the whole $\mathrm{NO}_{\mathrm{x}}$ gases, around $70 \%$, to be removed. To our knowledge, these high selectivity values are scarcely reported and only for some $\mathrm{TiO}_{2}$ advanced photocatalysts[11, 13, 49-52]. In fact, due to its poor selectivity, the $\mathrm{NO}_{x}$ removal observed for $\mathrm{TiO}_{2} \mathrm{P} 25$ is limited to $35 \%$. In agreement with our findings, low $\mathrm{NO}_{2}$ release was reported for a $\mathrm{ZnO}$ thin film De-NO photocatalyst[23] associated with the sensitivity of this oxide to $\mathrm{NO}_{2}$ gas[53]. On the other hand, $\mathrm{S}$ values of $\mathrm{ZnO} @ \mathrm{SiO}_{2}$ samples are higher than those of $\mathrm{ZnO}$ (samples $\mathrm{Zn}-2$ and $\mathrm{Zn}-4$ ). The influence of the $\mathrm{SiO}_{2}$ support on the ZnO crystalline growth allows microstructures with higher surface area and pore volume to be obtained, making the accessibility of reactant molecules to the active sites easier and therefore, facilitating the oxidation of $\mathrm{NO}$ and $\mathrm{NO}_{2}$ molecules. In this sense, the best performance for the $\mathrm{NO} \rightarrow \mathrm{HNO}_{2} \rightarrow \mathrm{NO}_{2} \rightarrow$ $\mathrm{NO}_{3}^{-}$oxidation process (reactions 3 to 7 ) was easily achieved by the $\mathrm{ZnO@SiO}$, photocatalysts. Additionally, the nitrogen oxide gases abatement performance of the last advanced De-NOx photocatalysts is compared in Table S3. From this table it is usually observed that the photocatalysts with higher NO efficiency values exhibited low De-NOx selectivity and the vice-versa. The NOx

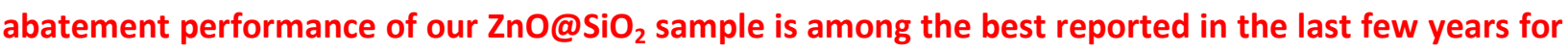


De-NOx photocatalysts as shown in Table S3, showing very high NO/NOx and S values, in similarity to BiOCl [54].

In order to confirm the mechanism proposed, which implies the selective formation and deposition of nitrite/nitrate onto the surface of the $\mathrm{ZnO} @ \mathrm{SiO}_{2}$ sample, additional evidences were obtained. FTIR measurement was used to qualitatively detect nitrogen oxide species on the surface before and after photocatalytic reactions, Figure $8 \mathrm{a}$. No bands concerning $\mathrm{N}-\mathrm{O}$ vibration modes were observed for the pristine sample. However, new absorption bands at 1258, 1327, 1375, 1518 and 1702 $\mathrm{cm}^{-1}$ appeared once the sample was subjected to the photocatalytic reaction, confirming the generation of nitrite/nitrate species during the PCO process. The bands located at 1518 and $1370 \mathrm{~cm}^{-1}$ correspond to stretching vibrations of nitrate species[55-57], whereas that at $1327 \mathrm{~cm}^{-1}$ is ascribed to nitrite ones $[57,58]$. The assignation of the band located at $1258 \mathrm{~cm}^{-1}$ could be ambiguously done for both nitrate $[57,59]$ and nitrite $[55,60]$ species. Finally, the band at $1710 \mathrm{~cm}^{-1}$ can be tentatively assigned to the adsorbed $\mathrm{NO}_{2}$ [59]. A more detailed assignment of IR bands attributed to $\mathrm{N}-\mathrm{O}$ stretching vibrations of surface nitrate $\left(\mathrm{NO}_{3}{ }^{-}\right)$and nitrite $\left(\mathrm{NO}_{2}{ }^{-}\right)$species is a difficult task, since $\mathrm{v}(\mathrm{N}-\mathrm{O})$ of different $\mathrm{NO}_{3}{ }^{-}$and $\mathrm{NO}_{2}^{-}$species fall in the same $1700-1000 \mathrm{~cm}^{-1}$ interval and their IR bands are strongly overlapped [55].

On the other hand, to shed light on differences found in De-NOx selectivity values, new evidence was obtained from preliminary $\mathrm{NO}_{2}$ adsorption studies carried out on $\mathrm{ZnO} @ \mathrm{SiO}_{2}, \mathrm{ZnO}$ and $\mathrm{TiO}_{2}-\mathrm{P} 25$ samples. Thus, a mixture of air/ $\mathrm{NO}_{2}$ was sent to the reactor with a $\mathrm{NO}_{2}$ concentration around $150 \mathrm{ppb}$, obtained by mixing synthetic air and pure $\mathrm{NO}_{2}$ (flow rate of $0.30 \mathrm{~L} \mathrm{~min}{ }^{-1} ;$ R.H. at $50 \pm 5$ ). In the absence of light irradiation, $\mathrm{NO}_{2}$ gas was passed over the samples and substantial differences were observed in the evolution of the concentration profile with time, Figure $8 \mathrm{~b}$. The $\mathrm{NO}_{2}$ concentration profile for $\mathrm{TiO}_{2}-$ P25 is similar to that of a blank test (without the presence of a catalyst). In both cases, the $\mathrm{NO}_{2}$ concentration remained constant at the initial inlet value during the time of the experiment, and therefore, there was no interaction between the gas and the catalyst or chamber surface. However, in the case of zinc oxide samples, lower concentration values for $\mathrm{NO}_{2}$ are measured during the first 30 minutes indicating that gas molecules are probably being adsorbed on their surface. This adsorption is 
higher for the dZn@RHA-4 sample because of its larger surface area compared to that of Zn-4. As aforementioned, the high De- $\mathrm{NO}_{\mathrm{x}}$ selectivity found for $\mathrm{ZnO} @ \mathrm{SiO}_{2}$ samples would be explained based on their ability to adsorb the recently formed $\mathrm{NO}_{2}$ gas molecule (reaction 3), facilitating its oxidation to nitrate before being released into the atmosphere. In the other hand, even though $\mathrm{ZnO}$ has the same band-gap energy as $\mathrm{TiO}_{2}$-anatase $(3.2 \mathrm{eV})$, its conduction band $(\mathrm{CB})$ is situated at a slightly higher energy level, which implies an increase in the reduction ability of the $C B$ electrons to form superoxide radicals $-\mathrm{O}_{2}^{-}[61,62]$. This would also favour the oxidation of the $\mathrm{NO}_{2}$ adsorbed molecules. Therefore, it can be summarized that the higher sensitivity of $\mathrm{ZnO} @ \mathrm{SiO}_{2}$ samples to $\mathrm{NO}_{2}$ gas greatly enhances the completion of $\mathrm{NO} \rightarrow \mathrm{HNO}_{2} \rightarrow \mathrm{NO}_{2} \rightarrow \mathrm{NO}_{3}{ }^{-}$photochemical oxidation process. Thus, the amount of $\mathrm{NO}_{2}$ toxic molecules which rose into the atmosphere during the photocatalytic reaction is negligible, making the use of De-NOx photocatalysts sustainable.

Finally, the potential practical application of these photocatalysts was qualitatively characterized by the evaluation of their reusability on large experiments. Figure 9 shows the diurnal mean values of NO concentration measured at an urban roadside in a highly populated city[6]. Because of the road traffic the NO concentration increases during the daytime, rapidly after sunrise and reaching its maximum level ( $\approx 180 \mathrm{ppbs}$ ) between 6.00 and 12.00 in the morning. It would seem of interest that De$\mathrm{NO}_{x}$ photocatalysts could serve to abate this main $\mathrm{NO}_{x}$ peak concentration level. In this sense, the dZn@RHA-4 sample was subjected to four consecutive NO photocatalytic removal experiments run in periods of 6 hours under similar NO concentrations. The data collected (Figure 9) suggest that most of the pollution peak is abated, around 110 ppbs of NO being removed by the photocatalytic action (from a NO inlet concentration of $150 \mathrm{ppb}$ ). The photocatalytic efficiency decreased slightly in the next three cycles, probably due to the nitrite/nitrate deposition masking the photoactive sites, thus hindering the photochemical performance, this loss of efficiency being similar to that obtained during a 24 hour light irradiation test (Figure S8). In fact, after the repeated photocatalytic test cycles, the mechanism proposed is again validated by the presence of nitrite/nitrate species in the corresponding FTIR spectra (Figure S9). Thus, after the fourth run, the sample was washed with water (filtered, collected 
and dried) in order to eliminate nitrite/nitrate species (as confirmed by FTIR, Figure S9). Even though there was a small amount of decay compared to the $4^{\text {th }}$ run (probably because the washing/drying procedure must be optimized in order to avoid particle aggregations), the efficiency exhibited in the next two runs $\left(5^{\text {th }}\right.$ and $\left.6^{\text {th }}\right)$ was similar, indicating good reusability. Moreover, the selectivity (data not

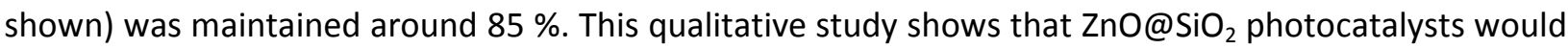
be highly useful in the abatement of the NO urban pollution. The photocatalysts were prepared by costeffective and easily scalable methodologies. As the De-NOx performance was similar enough for the four samples studied, avoiding the use of liquid solutions and decreasing the amount of energy used during the calcination process it is the preferred method for a potential industrialization of this synthetic procedure. Thus, the production of a mZn@RHA-2 sample would be preferred in which $20 \mathrm{~g}$ are easily obtained in only 3 hours of preparation at lab scale, indicating its favourable scalability.

\section{Conclusions}

A cost-effective and easily scalable methodology was reported in the preparation of a $\mathrm{ZnO}$ photocatalyst. By using simple procedures, liquid to solid deposition or mechanical milling, homogenous zinc acetate/rice husk mixtures were obtained by calcination at $600{ }^{\circ} \mathrm{C}$ thus obtaining $\mathrm{ZnO} @ \mathrm{SiO}_{2}$ samples. The $\mathrm{ZnO}$ particles, aggregated in spheres of different sizes, grow dispersed on the silica skeleton which also acts as a template. In comparison to pure zinc oxide obtained under the same experimental conditions, the use of a silica support enables a lower particle size, $70-180 \mathrm{~nm}$, and the highest surface area, $40-53 \mathrm{~m}^{2} \mathrm{~g}^{-1}$ to be obtained. Concerning the light absorption ability, $3.1-3.2 \mathrm{eV}$ band gap was estimated for ZnO@SiO2 samples.

When they are activated by sunlight, the $\mathrm{ZnO} @ \mathrm{SiO}_{2}$ samples act as catalysts in the NO photochemical oxidation. The PCO process occurs through the $\mathrm{NO} \rightarrow \mathrm{HNO}_{2} \rightarrow \mathrm{NO}_{2} \rightarrow \mathrm{NO}_{3}{ }^{-}$oxidation steps, as confirmed by the presence of nitrite/nitrate species on the catalyst's surface after the light induced reaction. High NO conversion values up to $75 \%$ are reached because of the high surface area exhibited by ZnO nanoparticles when grown on the silica skeleton, being limited to $50 \%$ for 
unsupported zinc oxide. It is worth mentioning the excellent De-NO selectivity values measured with $\mathrm{ZnO@SiO} 2$ photocatalyts, above $90 \%$, which allows removing approximately $70 \%$ of the $\mathrm{NO}_{\mathrm{x}}$ gases. In comparison, due to its poor selectivity, the $\mathrm{NO}_{\mathrm{x}}$ removal observed for the benchmark product $\mathrm{TiO}_{2} \mathrm{P} 25$ was limited to $35 \%$. Thus, by using $\mathrm{ZnO} @ \mathrm{SiO}_{2}$ samples the amount of $\mathrm{NO}_{2}$ gases, which rose into the atmosphere during the photocatalytic reaction, is negligible. This minimal appearance of the $\mathrm{NO}_{2}$ toxic molecules makes the use of De-NOx photocatalysts sustainable. The low emission of $\mathrm{NO}_{2}$ molecules is associated with the sensitivity of zinc oxide towards this gas. In fact, the preliminary adsorption essays indicated that $\mathrm{NO}_{2}$ gas is removed in the dark, in the presence of the $\mathrm{ZnO} @ \mathrm{SiO}_{2}$ sample. Moreover, this highly selective and sustainable photocatalyst exhibits high efficiency and recovery when operated under experimental conditions similar to $\mathrm{NO}_{\mathrm{x}}$ urban pollution periods (150 ppb NO; 6 hours), thus being proposed as a potential photocatalyst for air remediation. Because of their outstanding results of selectivity, further study will be addressed in the near future to ensure that the photocatalytic process works even more effectively. In this sense, metal doping would be an interesting strategy (preventing the recombination of the charge carriers), as we know that doped $\mathrm{ZnO}$ surpasses the photocatalytic efficiency of an un-doped one [63].

\section{Acknowledgements}

The Spanish (MINECO; MAT2017-88284-P) and Junta de Andalucía governments (PAI Groups FQM-214 and FQM-175) financed this work. Adrián Pastor acknowledges a grant from the Ministerio de Educación, Cultura y Deporte (FPU16/05041) to research at the University of Córdoba (Spain).

\section{Appendix A. Supplementary data}

Supplementary Information (SI) accompanying this paper includes more information about: the characterization of rice husk ash (SEM, XRD, Chemical analysis, $\mathrm{N}_{2}$ absorption isotherms); Experimental; Thermogravimetric analysis; Particle size distribution. 


\section{References}

[1] R. Vinu, G. Madras, Environmental remediation by photocatalysis, J. Indian Inst. Sci. 90 (2012) 189230.

[2] X. Li, J. Yu, M. Jaroniec, Hierarchical photocatalysts, Chem. Soc. Rev. 45 (2016) 2603-2636.

[3] J. Balbuena, M. Cruz-Yusta, L. Sánchez, Nanomaterials to Combat $\mathrm{NO}_{x}$ Pollution, J. Nanosci. Nanotechnol. 15 (2015) 6373-6385.

[4] M.W. Frampton, I.A. Greaves, $\mathrm{NO}_{\mathrm{x}}-\mathrm{NO}_{\mathrm{x}}$ : Who's There?, Am. J. Respir. Crit. Care. Med. 179 (2009) 1077-1078.

[5] Y. Chen, J. Borken-Kleefeld, $\mathrm{NO}_{\mathrm{x}}$ Emissions from Diesel Passenger Cars Worsen with Age, Environ. Sci. Technol. 50 (2016) 3327-3332.

[6] S.K. Pandey, K.-H. Kim, S.-Y. Chung, S.J. Cho, M.Y. Kim, Z.-H. Shon, Long-term study of $\mathrm{NO}_{\mathrm{x}}$ behavior at urban roadside and background locations in Seoul, Korea, Atmos. Environ. 42 (2008) 607-622.

[7] H. Nie, M. Ou, Q. Zhong, S. Zhang, L. Yu, Efficient visible-light photocatalytic oxidation of gaseous NO with graphitic carbon nitride $\left(\mathrm{g}-\mathrm{C}_{3} \mathrm{~N}_{4}\right)$ activated by the alkaline hydrothermal treatment and mechanism analysis, J. Hazard. Mater. 300 (2015) 598-606.

[8] J. Chen, C.-s. Poon, Photocatalytic construction and building materials: From fundamentals to applications, Build. Environ. 44 (2009) 1899-1906.

[9] S. Karapati, T. Giannakopoulou, N. Todorova, N. Boukos, I. Papailias, D. Dimotikali, C. Trapalis, Novel 'Pickering' modified $\mathrm{TiO}_{2}$ photocatalysts with high De-NOx efficiency, Catal. Today 287 (2017) 45-51.

[10] T. Giannakopoulou, I. Papailias, N. Todorova, N. Boukos, Y. Liu, J. Yu, C. Trapalis, Tailoring the energy band gap and edges' potentials of $\mathrm{g}-\mathrm{C}_{3} \mathrm{~N}_{4} / \mathrm{TiO}_{2}$ composite photocatalysts for $\mathrm{NO}_{\mathrm{x}}$ removal, Chem. Eng. J. 310 (2017) 571-580. 
[11] B. Tan, X. Zhang, Y. Li, H. Chen, X. Ye, Y. Wang, J. Ye, Anatase $\mathrm{TiO}_{2}$ Mesocrystals: Green Synthesis, In Situ Conversion to Porous Single Crystals, and Self-Doping $\mathrm{Ti}^{3+}$ for Enhanced Visible Light Driven Photocatalytic Removal of NO, Chem. Eur. J. 23 (2017) 5478-5487.

[12] N.C.T. Martins, J. Ângelo, A.V. Girão, T. Trindade, L. Andrade, A. Mendes, N-doped carbon quantum dots $/ \mathrm{TiO}_{2}$ composite with improved photocatalytic activity, Appl. Catal. B: Environ. 193 (2016) 67-74.

[13] J. Balbuena, J.M. Calatayud, M. Cruz-Yusta, P. Pardo, F. Martin, J. Alarcon, L. Sanchez, Mesocrystalline anatase nanoparticles synthesized using a simple hydrothermal approach with enhanced light harvesting for gas-phase reaction, Dalton Trans. (2018).

[14] E.C. Agency, ANNEX 2 - Comments and response to comments on CLH proposal on titanium dioxide, 2017.

[15] J. Balbuena, M. Cruz-Yusta, A. Pastor, L. Sánchez, $\alpha-\mathrm{Fe}_{2} \mathrm{O}_{3} / \mathrm{SiO}_{2}$ composites for the enhanced photocatalytic NO oxidation, J. Alloys Compd. 735 (2018) 1553-1561.

[16] J. Luo, G. Dong, Y. Zhu, Z. Yang, C. Wang, Switching of semiconducting behavior from n-type to ptype induced high photocatalytic NO removal activity in $\mathrm{g}^{-} \mathrm{C}_{3} \mathrm{~N}_{4}$, Appl. Catal. B: Environ. 214 (2017) 4656.

[17] F. Dong, T. Xiong, Z. Zhao, Y. Sun, M. Fu, Ammonia induced formation of $\mathrm{N}$-doped $(\mathrm{BiO})_{2} \mathrm{CO}_{3}$ hierarchical microspheres: the effect of hydrothermal temperature on the morphology and photocatalytic activity, CrystEngComm 15 (2013) 10522-10532.

[18] Z. Ai, W. Ho, S. Lee, L. Zhang, Efficient Photocatalytic Removal of NO in Indoor Air with Hierarchical Bismuth Oxybromide Nanoplate Microspheres under Visible Light, Environ. Sci. Technol. 43 (2009) 41434150.

[19] Y. Gao, Y. Huang, Y. Li, Q. Zhang, J.-j. Cao, W. Ho, S.C. Lee, Plasmonic Bi/ZnWO ${ }_{4}$ Microspheres with Improved Photocatalytic Activity on NO Removal under Visible Light, ACS Sustain. Chem. Eng. 4 (2016) 6912-6920. 
[20] S. Zhu, L. Lu, Z. Zhao, T. Wang, X. Liu, H. Zhang, F. Dong, Y. Zhang, Mesoporous Ni-Doped $\delta-\mathrm{Bi}_{2} \mathrm{O}_{3}$ Microspheres for Enhanced Solar-Driven Photocatalysis: A Combined Experimental and Theoretical Investigation, J. Phys. Chem. C 121 (2017) 9394-9401.

[21] K.B. Kim, Y.W. Kim, S.K. Lim, T.H. Roh, D.Y. Bang, S.M. Choi, D.S. Lim, Y.J. Kim, S.H. Baek, M.K. Kim, H.S. Seo, M.H. Kim, H.S. Kim, J.Y. Lee, S. Kacew, B.-M. Lee, Risk assessment of zinc oxide, a cosmetic ingredient used as a UV filter of sunscreens, J. Toxicol. Environ. Health B 20 (2017) 155-182.

[22] C.C. Pei, W.W.-F. Leung, Enhanced photocatalytic activity of electrospun $\mathrm{TiO}_{2} / \mathrm{ZnO}$ nanofibers with optimal anatase/rutile ratio, Catal. Commun. 37 (2013) 100-104.

[23] N. Todorova, T. Giannakopoulou, K. Pomoni, J. Yu, T. Vaimakis, C. Trapalis, Photocatalytic NOx oxidation over modified $\mathrm{ZnO} / \mathrm{TiO}_{2}$ thin films, Catal. Today 252 (2015) 41-46.

[24] E. Kowsari, S. Abdpour, Investigation performance of rod-like $\mathrm{ZnO} / \mathrm{CdO}$ composites, synthesized in ionic liquid medium as photocatalytic for degradation of air pollutants $\left(\mathrm{SO}_{2}\right.$ and $\left.\mathrm{NO}_{\mathrm{x}}\right)$, Optik $127(2016)$ 11567-11576.

[25] E. Kowsari, S. Abdpour, In-situ functionalization of mesoporous hexagonal ZnO synthesized in task specific ionic liquid as a photocatalyst for elimination of $\mathrm{SO}_{2}, \mathrm{NO}_{x}$, and $\mathrm{CO}$, J. Solid State Chem. 256 (2017) 141-150.

[26] E. Kowsari, B. Bazri, Synthesis of rose-like ZnO hierarchical nanostructures in the presence of ionic liquid/ $\mathrm{Mg}^{2+}$ for air purification and their shape-dependent photodegradation of $\mathrm{SO}_{2}, \mathrm{NO}_{\mathrm{x}}$, and $\mathrm{CO}$, Appl. Catal. A: Gen. 475 (2014) 325-334.

[27] Y. Huang, C. Guo, L. Huang, Q. Dong, S. Yin, T. Sato, Photocatalytic oxidation of $\mathrm{NO}_{x}$ gases using ZnO with superstructure by a low temperature soft solution process, Int. J. Nanotechnol. 10 (2012) 30-37. [28] Y. Wei, Y. Huang, J. Wu, M. Wang, C. Guo, D. Qiang, S. Yin, T. Sato, Synthesis of hierarchically structured $\mathrm{ZnO}$ spheres by facile methods and their photocatalytic De- $\mathrm{NO}_{\mathrm{x}}$ properties, J. Hazard. Mater. 248-249 (2013) 202-210. 
[29] F. Adam, J.N. Appaturi, R. Thankappan, M.A.M. Nawi, Silica-tin nanotubes prepared from rice husk ash by sol-gel method: Characterization and its photocatalytic activity, Appl. Surf. Sci. 257 (2010) 811816.

[30] Y. Li, J.Y. Lan, J. Liu, J. Yu, Z. Luo, W. Wang, L. Sun, Synthesis of Gold Nanoparticles on Rice Husk Silica for Catalysis Applications, Ind. Eng. Chem. Res. 54 (2015) 5656-5663.

[31] A. Jaroenworaluck, N. Pijarn, N. Kosachan, R. Stevens, Nanocomposite $\mathrm{TiO}_{2}-\mathrm{SiO}_{2}$ gel for UV absorption, Chem. Eng. J. 181-182 (2012) 45-55.

[32] H. Chen, L. Zhao, Y. Xiang, Y. He, G. Song, X. Wang, F. Liang, A novel Zn- $\mathrm{TiO}_{2} / \mathrm{C} @ \mathrm{SiO}_{2}$ nanoporous material on rice husk for photocatalytic applications under visible light, Desalination and Water Treatment 57 (2016) 9660-9670.

[33] C. Tian, Q. Zhang, A. Wu, M. Jiang, Z. Liang, B. Jiang, H. Fu, Cost-effective large-scale synthesis of ZnO photocatalyst with excellent performance for dye photodegradation, Chem. Commun. 48 (2012) 2858-2860.

[34] P. Sujaridworakun, S. Jinawath, W. Panpa, A. Nakajima, M. Yoshimura, Hydrothermal Synthesis of TiO2/SiO2 Hybrid Photocatalyst from Rice Husk Ash, Key Eng. Mater. 352 (2007) 281-285.

[35] ISO, Fine ceramics (advanced ceramics, advanced technical ceramics) -- Test method for airpurification performance of semiconducting photocatalytic materials -- Part 1: Removal of nitric oxide, in: ISO (Ed.), International Organization for Standardization, 2007.

[36] F. Rodriguez-Rivas, A. Pastor, C. Barriga, M. Cruz-Yusta, L. Sánchez, I. Pavlovic, Zn-Al layered double hydroxides as efficient photocatalysts for NOx abatement, Chem. Eng. J. 346 (2018) 151-158.

[37] M.E. Monge, B. D'Anna, C. George, Nitrogen dioxide removal and nitrous acid formation on titanium oxide surfaces -an air quality remediation process?, Phys. Chem. Chem. Phys. 12 (2010) 89918998.

[38] T.S.T. da Silva Gelson, T.G. Carvalho Kele, F. Lopes Osmando, S. Gomes Eliziana, R. Malagutti Andréa, R. Mastelaro Valmor, C. Ribeiro, A.J.L. Mourão Henrique, Synthesis of ZnO Nanoparticles 
Assisted by $\mathrm{N}$ Sources and their Application in the Photodegradation of Organic Contaminants, ChemCatChem 9 (2017) 3795-3804.

[39] L. Shi, P. Zhu, R. Yang, X. Zhang, J. Yao, F. Chen, X. Gao, P. Ai, N. Tsubaki, Functional rice husk as reductant and support to prepare as-burnt $\mathrm{Cu}$-ZnO based catalysts applied in low-temperature methanol synthesis, Catal. Commun. 89 (2017) 1-3.

[40] L.A. O'Dell, S.L.P. Savin, A.V. Chadwick, M.E. Smith, Structural studies of silica- and alumina-pinned nanocrystalline $\mathrm{SnO}_{2}$, Nanotechnology 16 (2005) 1836.

[41] S.G. Kumar, K.S.R.K. Rao, Zinc oxide based photocatalysis: tailoring surface-bulk structure and related interfacial charge carrier dynamics for better environmental applications, RSC Adv. 5 (2015) 3306-3351.

[42] A.E. Ahmed, F. Adam, The benzylation of benzene using aluminium, gallium and iron incorporated silica from rice husk ash, Microporous Mesoporous Mater. 118 (2009) 35-43.

[43] S. Vives, C. Meunier, Optical properties of copper modified sol-gel $\mathrm{SiO}_{2}$ thin films, Mater. Lett. 91 (2013) 165-169.

[44] S. Kaviya, E. Prasad, Eco-friendly synthesis of $\mathrm{ZnO}$ nanopencils in aqueous medium: a study of photocatalytic degradation of methylene blue under direct sunlight, RSC Adv. 6 (2016) 33821-33827.

[45] A.K. Zak, M.E. Abrishami, W.H.A. Majid, R. Yousefi, S.M. Hosseini, Effects of annealing temperature on some structural and optical properties of $\mathrm{ZnO}$ nanoparticles prepared by a modified sol-gel combustion method, Ceram. Int. 37 (2011) 393-398.

[46] S. Devahasdin, C. Fan Jr, K. Li, D.H. Chen, $\mathrm{TiO}_{2}$ photocatalytic oxidation of nitric oxide: transient behavior and reaction kinetics, J. Photochem. Photobiol. A 156 (2003) 161-170.

[47] R.J. Lewis, N.I. Sax, Sax's Dangerous Properties of Industrial Materials, 12th ed., Van Nostrand Reinhold, New York, 2012.

[48] M.J. Hernández Rodríguez, E. Pulido Melián, O. González Díaz, J. Araña, M. Macías, A. González Orive, J.M. Doña Rodríguez, Comparison of supported $\mathrm{TiO}_{2}$ catalysts in the photocatalytic degradation of NO , J. Mol. Catal. A: Chem. 413 (2016) 56-66. 
[49] J. Ma, H. Wu, Y. Liu, H. He, Photocatalytic Removal of $\mathrm{NO}_{x}$ over Visible Light Responsive OxygenDeficient $\mathrm{TiO}_{2}$, J. Phys. Chem. C 118 (2014) 7434-7441.

[50] N. Todorova, T. Giannakopoulou, S. Karapati, D. Petridis, T. Vaimakis, C. Trapalis, Composite $\mathrm{TiO}_{2}$ /clays materials for photocatalytic $\mathrm{NO}_{x}$ oxidation, Appl. Surf. Sci. 319 (2014) 113-120.

[51] A. Trapalis, N. Todorova, T. Giannakopoulou, N. Boukos, T. Speliotis, D. Dimotikali, J. Yu, $\mathrm{TiO}_{2}$ /graphene composite photocatalysts for $\mathrm{NO}_{\mathrm{X}}$ removal: A comparison of surfactant-stabilized graphene and reduced graphene oxide, Appl. Catal. B: Environ. 180 (2016) 637-647.

[52] A.V. Katsanaki, A.G. Kontos, T. Maggos, M. Pelaez, V. Likodimos, E.A. Pavlatou, D.D. Dionysiou, P. Falaras, Photocatalytic oxidation of nitrogen oxides on N-F-doped titania thin films, Appl. Catal. B: Environ. 140-141 (2013) 619-625.

[53] S. Öztürk, N. Kılınç, N. Taşaltin, Z.Z. Öztürk, A comparative study on the $\mathrm{NO}_{2}$ gas sensing properties of ZnO thin films, nanowires and nanorods, Thin Solid Films 520 (2011) 932-938.

[54] H. Li, H. Shang, X. Cao, Z. Yang, Z. Ai, L. Zhang, Oxygen Vacancies Mediated Complete Visible Light NO Oxidation via Side-On Bridging Superoxide Radicals, Environ. Sci. Technol. 52 (2018) 8659-8665.

[55] R.V. Mikhaylov, A.A. Lisachenko, B.N. Shelimov, V.B. Kazansky, G. Martra, S. Coluccia, FTIR and TPD Study of the Room Temperature Interaction of a NO-Oxygen Mixture and of $\mathrm{NO}_{2}$ with Titanium Dioxide, J. Phys. Chem. C 117 (2013) 10345-10352.

[56] R. Sugrañez, J. Balbuena, M. Cruz-Yusta, F. Martín, J. Morales, L. Sánchez, Efficient behaviour of hematite towards the photocatalytic degradation of $\mathrm{NO}_{x}$ gases, Appl. Catal. B: Environ. 165 (2015) 529536.

[57] K.I. Hadjiivanov, Identification of neutral and charged $\mathrm{N}_{X} \mathrm{O}_{Y}$ surface species by IR spectroscopy, Catal. Rev. Sci. Eng. 42 (2000) 71-144.

[58] J. Sá, J.A. Anderson, FTIR study of aqueous nitrate reduction over $\mathrm{Pd} / \mathrm{TiO}_{2}$, Appl. Catal. B: Environ. 77 (2008) 409-417.

[59] B. Zhao, R. Ran, X. Wu, D. Weng, X. Wu, C. Huang, Comparative study of $\mathrm{Mn} / \mathrm{TiO}_{2}$ and $\mathrm{Mn} / \mathrm{ZrO}_{2}$ catalysts for NO oxidation, Catal. Commun. 56 (2014) 36-40. 
[60] Y. Duan, M. Zhang, L. Wang, F. Wang, L. Yang, X. Li, C. Wang, Plasmonic Ag-TiO ${ }_{2-x}$ nanocomposites for the photocatalytic removal of NO under visible light with high selectivity: The role of oxygen vacancies, Appl. Catal. B: Environ. 204 (2017) 67-77.

[61] A.L. Linsebigler, G. Lu, J.T. Yates, Photocatalysis on $\mathrm{TiO}_{2}$ Surfaces: Principles, Mechanisms, and Selected Results, Chem. Rev. 95 (1995) 735-758.

[62] T. Giannakopoulou, I. Papailias, N. Todorova, N. Boukos, Y. Liu, J. Yu, C. Trapalis, Tailoring the energy band gap and edges' potentials of g-C3N4/TiO2 composite photocatalysts for NOx removal, Chem. Eng. J. 310 (2017) 571-580.

[63] K.M. Lee, C.W. Lai, K.S. Ngai, J.C. Juan, Recent developments of zinc oxide based photocatalyst in water treatment technology: a review, Water Res. 88 (2016) 428-448. 


\section{Figure Captions}

Figure 1: XRD patterns for dZn@RHA, mZn@RHA and Zn samples.

Figure 2: SEM images for dZn@RHA-2 (a, c) and dZn@RHA-4 (b, d) samples.

Figure 3: SEM images for mZn@RHA-2 (a, c), mZn@RHA-4 (b, d), Zn-2 (e) and Zn-4 (f) samples.

Figure 4: $\mathrm{N}_{2}$ adsorption-desorption isotherm and pore size distribution for dZn@RHA, Zn@RHA and Zn samples.

Figure 5: Kubelka-Munk transformed reflectance spectra for Zn@RHA (a) and Zn (b) samples.

Figure 6: Nitrogen oxides concentration profiles obtained during the photo-degradation of gaseous NO under light irradiation ondZn@RHA, mZn@RHA and Zn samples.

Figure 7: $\mathrm{NO}$ conversion (\%, blue), $\mathrm{NO}_{2}$ released (\%, orange), $\mathrm{NO}_{\mathrm{x}}$ conversion (\%, grey) and Selectivity values (\%, yellow) for dZn-RHA, mZn-RHA, $\mathrm{Zn}$ and $\mathrm{TiO}_{2}-\mathrm{P} 25$ samples.

Figure 8: (a) IR spectra obtained for dZn@RHA-4 sample before and after light irradiation. (b) $\mathrm{NO}_{2}$ concentration profiles obtained in dark condition for $\mathrm{Zn}-4$, dZn@RHA-4 and $\mathrm{TiO}_{2}$ samples. Red line marks the $\mathrm{NO}_{2}$ inlet concentration.

Figure 9: Diurnal distribution pattern of NO gas at urban roadside (grey shading) and NO concentration profile obtained for dZn@RHA-4 sample (o) at different runs during 6 hours of light irradiation (NO inlet concentration: $150 \mathrm{ppb}$ ). The sample was washed and dried after the $4^{\text {th }}$ run. 
ZnO on rice husk: a sustainable photocatalyst for urban air purification

Adrián Pastor, José Balbuena, Manuel Cruz-Yusta, Ivana Pavlovic and Luis Sánchez*

Departamento de Química Inorgánica, Instituto Universitario de Investigación en Química Fina y Nanoquímica IUIQFN, Universidad de Córdoba, Campus de Rabanales, E-14071 Córdoba, España.

* Corresponding Author:

- Prof. Luis Sánchez

ORCID ID: 0000-0002-0194-1908

Departamento de Química Inorgánica, Instituto Universitario de Investigación en Química Fina y Nanoquímica IUIQFN, Universidad de Córdoba, Campus de Rabanales, E-14071 Córdoba, España.

E-mail: luis-sanchez@uco.es

Tel: +00-34-957-218634 


\section{Abstract}

A cost-effective and sustainable De-NOx photocatalyst is prepared using zinc acetate and rice husk. $\mathrm{ZnO} @ \mathrm{SiO}_{2}$ samples are obtained from the calcination of a homogenised precursor mixture at $600{ }^{\circ} \mathrm{C}$. $\mathrm{ZnO}$ nanoparticles $(70-180 \mathrm{~nm})$ grow aggregated in spheres and well dispersed $\left(40-53 \mathrm{~m}^{2} \mathrm{~g}^{-1}\right.$ surface area) covering the silicon skeleton. The corresponding band gap for $\mathrm{ZnO} @ \mathrm{SiO}_{2}$ photocatalysts was estimated at $3.1-3.2 \mathrm{eV}$. When the samples are irradiated by sunlight in a nitrogen oxide atmosphere the $\mathrm{NO} \rightarrow \mathrm{HNO}_{2} \rightarrow \mathrm{NO}_{2} \rightarrow \mathrm{NO}_{3}^{-}$photochemical oxidation takes place. In comparison to unsupported $\mathrm{ZnO}$ and $\mathrm{TiO}_{2}-\mathrm{P} 25, \mathrm{ZnO} @ \mathrm{SiO}_{2}$ samples exhibit high $\mathrm{NO}_{\mathrm{x}}$ removal values $(70 \%)$ and outstanding selectivity (>90\%), the latter related to the sensitivity of zinc oxide towards $\mathrm{NO}_{2}$ gas. This new photocatalyst is easily recyclable and reusable.

\section{$\underline{\text { Keywords }}$}

Zinc oxide, Photocatalyst, Nitrogen oxides 


\section{Introduction}

Semiconductor (SC) photocatalysts have been widely studied as suitable materials for environmental remediation. A multitude of compounds, based mainly on $\mathrm{TiO}_{2}, \mathrm{ZnO}, \mathrm{CdS}, \mathrm{Fe}_{2} \mathrm{O}_{3}$ and $\mathrm{WO}_{3}$, were reported for the photocatalytic degradation of a variety of water, air and solid pollutants[1, 2]. In the recent years, an increasing interest has arisen in the study of the photochemical oxidation (PCO) of nitrogen oxide gases as a sustainable tool to combat urban air pollution[3].

Because of their toxicity, the presence of nitrogen oxides, commonly referred as $\mathrm{NO}_{\mathrm{x}}-$ nitric oxide (NO) and nitrogen dioxide $\left(\mathrm{NO}_{2}\right)^{-}$, in the urban environment is a high risk for human health[4]. Thus, environmental agencies in the USA and European Community limit the hourly $\mathrm{NO}_{\mathrm{x}}$ air concentration to $0.1 \mathrm{ppm}$ and $0.2 \mathrm{ppm}$, respectively. However, these limits are difficult to be attained because the $\mathrm{NO}_{\mathrm{x}}$ emissions rates from older vehicles worsen as time goes on[5]. In fact, nowadays higher $\mathrm{NO}_{x}$ levels are measured in very populated cities all over the world and thousands of early deaths worldwide are associated with these $\mathrm{NO}_{\mathrm{x}}$ emissions $[6,7]$. Today's research works have demonstrated the potential applicability of semiconductors in directly removing large amounts of $\mathrm{NO}_{\mathrm{x}}$ gases (De- $\mathrm{NO}_{\mathrm{x}}$ action) from the urban centres in our cities. In fact, at present, depolluting building materials, using $\mathrm{TiO}_{2}$ as a photocatalytic additive, are integrated in some advanced buildings in an attempt to achieve effective $\mathrm{NO}_{\mathrm{x}}$ de-pollution in urban areas[8]. In this sense, many researchers pay attention to the preparation of modified titania with enhanced $\mathrm{De}-\mathrm{NO}_{\mathrm{x}}$ photocatalytic performance[9-13].

However, it's necessary to point out that $\mathrm{TiO}_{2}$ has just been proposed to be classified as possibly causing cancer when inhaled[14]. This could limit some of its applications and, therefore, a rapid advance in the study and development of new De-NOx photocatalysts is desired. $\mathrm{g}-\mathrm{C}_{3} \mathrm{~N}_{4}, \mathrm{~N}-(\mathrm{BiO})_{2} \mathrm{CO}_{3}$, $\mathrm{BiOBr}, \mathrm{Bi} / \mathrm{ZnWO}_{4}$, or $\mathrm{Ni}-\mathrm{Bi}_{2} \mathrm{O}_{3}$ among others, were reported as alternative materials towards the photochemical NO abatement[15-20]. In this work we study the De- $\mathrm{NO}_{x}$ ability of $\mathrm{ZnO}$, which is not considered to be a threat to consumers health[21]. Even though $\mathrm{ZnO}$ is a preferred photocatalyst because of its high photosensitivity, mechanical-thermal stability and tuneable morphology, only a few studies have been recently reported for this specific environmental application. Some of them are 
devoted to enhancing titanium dioxide $\mathrm{De}-\mathrm{NO}_{\mathrm{x}}$ efficiency through the preparation of $\mathrm{TiO}_{2} / \mathrm{ZnO}$ composites[22, 23]. In the case of a pure $\mathrm{ZnO}$ photocatalyst, whose preparation proceeded by using amine derivatives or ionic liquids, the NO conversion photo-efficiency was equal to or lower than 50 $\%[24-28]$. On the other hand, the preparation of $\mathrm{ZnO}$ spheres by a carbon template via the one-step process is highly interesting, the resulting compound showing the highest photocatalytic activity[28]. Herein we propose a very simple procedure that allows us to obtain a $\mathrm{ZnO}$ efficient photocatalyst by using rice husk ash (RHA) as a support, a strategy successfully employed in the preparation of metals and metal oxides (photo)catalysts[29-32]. Rice husk (RH) is an agricultural waste product, the ash of which contains about $92-95 \%$ silica $\left(\mathrm{SiO}_{2}\right)[29]$, and when used to synthesize silica nanoparticles, offers additional advantages, including greener raw materials, lower costs, and higher sustainability[30]. The

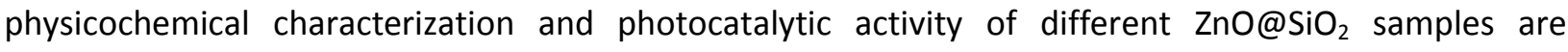
presented. Remarkably, as the main novelty, $\mathrm{De}-\mathrm{NO}_{\mathrm{x}} \mathrm{ZnO}$ based photocatalysts are prepared using a cost-effective and large-scale synthetic procedure and exhibiting the highest NO photo-chemical conversion efficiency and selectivity values reported. Due to the high selectivity values found, the use of photocatalysis proves to be sustainable as a NO abatement process.

\section{Materials and methods}

\subsection{Preparation of ZnO supported photocatalyst}

The complete characterization of RHA support is provided in Supplementary Information (SI; Figures S1 - S4 and Table S1). With the aim of obtaining a cost-effective and large-scale synthesis procedure in mind, the methodology used for the preparation of a photocatalyst was as simple as possible. Zinc acetate is a very cheap salt that is successfully used in the synthesis of ZnO-based materials[33]. $\mathrm{Zn}(\mathrm{OAc})_{2} \cdot 2 \mathrm{H}_{2} \mathrm{O}(99,0 \%$, Sigma-Aldrich) and $\mathrm{RH}$ were used as precursor components, in the 0.65 weight ratio. This ratio was selected following that previously reported as optimum in the preparation of a catalyst on RHA as a support[34], focussing the attention of this preliminary work in the 
preparative methodology. Two methods were chosen in order to enhance the contact between the precursor components:

i) Liquid to solid deposition. $30.73 \mathrm{~g}$ of $\mathrm{Zn}(\mathrm{OAc})_{2} \cdot 2 \mathrm{H}_{2} \mathrm{O}$ was dissolved in $150 \mathrm{~mL}$ of milliQ water. Subsequently, $20 \mathrm{~g}$ of RH was added to the vessel. After $30 \mathrm{~min}$ of magnetic stirring, the paste was dried at $80{ }^{\circ} \mathrm{C}$ for 4 days. Later, the product was calcined at $600{ }^{\circ} \mathrm{C}$ for 2 and 4 hours. The photocatalyst samples obtained were denominated as dZn@RHA-2 and dZn@RHA-4, respectively.

ii) Mechanical milling. A mixture of $30.73 \mathrm{~g}$ of $\mathrm{Zn}(\mathrm{OAc})_{2} \cdot 2 \mathrm{H}_{2} \mathrm{O}$ and $20 \mathrm{~g}$ of $\mathrm{RH}$ was milled using a planetary mill (45 min, $300 \mathrm{rpm}$ ). The collected product was calcined at $600{ }^{\circ} \mathrm{C}$ for 2 and 4 hours. The photocatalyst samples obtained were denominated as mZn@RHA-2 and mZn@RHA-4, respectively.

\subsection{Sample characterization}

Energy Dispersive X-ray Fluorescence analysis (XRF) was done in a ZSX Primus IV (Rigaku) equipment. The carbon content elemental analysis was determined by using an Eurovector EA 3000 elemental instrument. Crystalline phases were identified by using X-ray diffraction (XRD). The XRD patterns were recorded in a Bruker D8 Discover A25 diffractometer. The crystal size of the samples was determined by means of the Scherrer equation. This equation was calculated with DIFFRACT.EVA V3.1 software. The morphology of the samples was examined by scanning electron microscopy (SEM). SEM images were obtained with a Jeol JMS-6400 microscope. Particle size distribution was estimated using a Visiolog 6.1 software. Nitrogen absorption isotherms were obtained at $77.4 \mathrm{~K}$ on an ASAP 2020 instrument from Micromeritics, from which the specific surface areas were calculated using the multipoint BrunauerEmmett-Teller (BET) and Barrett-Joyner-Halenda (BJH) methods. Diffuse reflectance (DR) spectra were recorded using a Varian Cary 1E spectrophotometer. Thermogravimetry (TGA) was carried out with a Mettler Toledo in air atmosphere (flow: $100 \mathrm{~mL} \mathrm{~min}{ }^{-1}$ ) from room temperature to $600{ }^{\circ} \mathrm{C}$ (heating rate of $\left.10^{\circ} \mathrm{C} \mathrm{min}^{-1}\right)$. 
Additional information is provided in SI.

\subsection{Photocatalytic activity tests}

The photocatalytic activity of the materials towards the oxidation of NO was studied using a protocol similar to the standardised test method developed for the characterisation of air-purification performance, ISO 22197-1 [35]. However, some of the specifications described in this standard were modified in order to obtain better performance with the samples of this study. Thus, the tests were carried out on a $50 \mathrm{~mm} \times 50 \mathrm{~mm}$ sample holder placed in a laminar flow reactor [35]. Artificial sunlight irradiation (Solarbox 3000e RH light irradiation box) was obtained with an Xe lamp with controlled irradiance ( 25 and $580 \mathrm{Wm}^{-2}$ for UV and visible, respectively). For each De-NO $\mathrm{x}$ test, $1.0 \mathrm{~g}$ of the sample supported on the sampler holder inside the reactor was used. As a pollutant, a mixture of air/NO was sent to the photoreactor with a NO concentration of $150 \mathrm{ppb}$ (obtained by mixing synthetic air and pure NO). This concentration was chosen because it is representative of NO concentrations found during intense photochemical pollution periods in urban environments [6], having already been successfully adopted in previous research works $[15,36,37]$. The gas mixture was supplied by using a flow rate of $0.30 \mathrm{~L} \mathrm{~min}^{-1}$ and fixing the relative humidity at $50 \pm 5 \%$. The measurement of the concentration of NO, $\mathrm{NO}_{\mathrm{x}}$ and $\mathrm{NO}_{2}$ gases was carried out using a chemiluminescence analyser (model Environnement AC32M). Each test was repeated three times to obtain average concentration values. The calculated standard deviations were $\pm 0.3 \mathrm{ppb}$ for $\mathrm{NO}$ concentration and $\pm 1.0 \mathrm{ppb}$ for $\mathrm{NO}_{2}$ and $\mathrm{NO}_{\mathrm{x}}$ concentrations. The photocatalytic efficiency was evaluated following the $\mathrm{NO}$ conversion (\%), $\mathrm{NO}_{2}$ released (\%) and $\mathrm{NO}_{\mathrm{x}}$ conversion (\%) parameters (defined in SI). 


\section{Results and discussion}

\subsection{Photocatalyst characterisation}

$\mathrm{ZnO@SiO}{ }_{2}$ supported photocatalysts were obtained after the calcination of the $\mathrm{Zn}(\mathrm{OAc})_{2} / \mathrm{RH}$ precursor mixtures. The chemical composition of samples is provided in Table S2. The XRD patterns obtained for the four samples are shown in Figure 1 . Only peaks ascribable to hkl reflections of hexagonal structure of $\mathrm{ZnO}$ (wurtzite) were detected. The diffraction peaks at $31.5^{\circ}, 34.2^{\circ}, 36.1^{\circ}, 47.3^{\circ}$, $56.4^{\circ}, 62.7^{\circ}, 66.1^{\circ}, 67.7^{\circ}$ and $68.9^{\circ}$ two theta degrees can be attributed to (100), (002), (101), (102), (110), (103), (200), (112) and (201) crystal planes, respectively[38]. Apart from its amorphous character, the negligible presence of the silica halo expected at $22^{\circ}$ (Fig S5)[39] would be indicative of good zinc oxide covering on the silica support. For comparison purposes, $\mathrm{ZnO}$ without the use of $\mathrm{RH}$ was also prepared using the same calcination procedure. The $\mathrm{ZnO}$ samples thus obtained after 2 and 4 hours of calcination were labelled as Zn-2 and Zn-4, respectively. Their corresponding XRD patterns also show the formation of pure zinc oxide. In the case of silica supported samples, the intensity of diffraction peaks is significantly lower than that observed for $\mathrm{Zn}-2$ and $\mathrm{Zn}-4$ samples. Thus, the smallest crystallite size

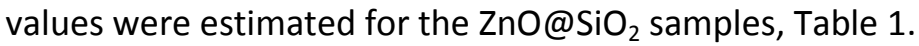

The SEM images for dZn@RHA samples, Figure 2, show ZnO particles growing dispersed on the cob-shaped skeleton, being aggregated in spheres of different sizes. The milling process breaks this skeleton but similar particle aggregation is observed for mZn@RHA samples, Figure 3 (a-d). In both cases, the wurtzite particle size is around 70-180 $\mathrm{nm}$ (Figure S6a). For the whole set of samples, the silica support (Supplementary Information) appears completely covered by ZnO particles, as expected from XRD patterns. The extended heating period of up to 4 hours had no significant influence on the morphology of the $\mathrm{ZnO}$ crystals. The silica skeleton acts as a support but also as a template influencing the growth of the wurtzite crystals. Thus, without the use of $\mathrm{RH}$, the $\mathrm{ZnO}$ is constituted by independent larger amorphous nanoparticles of 140-280 nm, Figure $3(\mathrm{e}, \mathrm{f})$ and Figure S6b. 
The differences observed in $\mathrm{ZnO}$ crystallite size and morphology, with and without the use of $\mathrm{RH}$, clearly reveal the influence of rice husk on the $\mathrm{ZnO}$ growth. This could be explained by assuming the following crystal growth mechanism. Since the RH decomposes at a lower temperature than the zinc acetate precursor (Figure S1), ZnO crystallizes once the amorphous silica is formed. By considering the appearance of the Zener pinning process[40], the growth of the first ZnO crystals must be restricted by the presence of silica as an inert phase, which is believed to result in tiny discrete particles located in the interface regions between the emergent $\mathrm{ZnO}$ nanocrystals. These reduce the radius of the crystallite surfaces, thus increasing the energy required for growth. This would explain the limited size of $\mathrm{ZnO}$ crystals and nanoparticles in Zn@RHA samples (Figure S6; Table 1).

Table 1. The surface analysis parameters and crystallite size for zinc oxide samples

\begin{tabular}{|c|c|c|c|c|c|c|c|}
\hline Sample & $\begin{array}{c}\text { BET } \\
\text { surface } \\
\text { area } \\
\left(\mathrm{m}^{2} \cdot \mathrm{g}^{-1}\right) \\
\end{array}$ & $\begin{array}{c}\mathrm{BJH}^{*} \\
\text { pore } \\
\text { volume } \\
\left(\mathrm{cm}^{3} \cdot \mathrm{g}^{-1}\right) \\
\end{array}$ & $\begin{array}{c}\text { BJH* }^{*} \\
\text { mesoporous } \\
\text { volume } \\
\left(\mathrm{cm}^{3} \cdot \mathrm{g}^{-1}\right) \\
\end{array}$ & $\begin{array}{c}\text { BJH* }^{*} \\
\text { average pore } \\
\text { diameter } \\
(\mathrm{nm}) \\
\end{array}$ & $\begin{array}{c}\text { BJH* }^{*} \\
\text { surface } \\
\text { area } \\
\left(\mathrm{m}^{2} \cdot \mathrm{g}^{-1}\right) \\
\end{array}$ & $\begin{array}{c}\text { BJH* } \\
\text { mesoporous } \\
\text { surface area } \\
\left(\mathrm{m}^{2} \cdot \mathrm{g}^{-1}\right) \\
\end{array}$ & $\begin{array}{c}\text { Crystallite } \\
\text { size } \\
(\mathrm{nm})\end{array}$ \\
\hline dZn@RHA-2 & 49,3 & 0,11 & 0,08 & 8,99 & 48,5 & 42,3 & 23,6 \\
\hline dZn@RHA-4 & 53,5 & 0,13 & 0,1 & 9,00 & 56,2 & 49,5 & 25,0 \\
\hline mZn@RHA-2 & 40,3 & 0,11 & 0,08 & 9,00 & 47,1 & 41,5 & 32,7 \\
\hline mZn@RHA-4 & 50,7 & 0,10 & 0,07 & 8,66 & 45,1 & 38,8 & 36,9 \\
\hline $\mathrm{Zn}-2$ & 4,5 & 0,01 & 0,01 & 17,15 & 3,3 & 2,5 & 62,0 \\
\hline$Z n-4$ & 2,8 & 0,01 & 0,01 & 21,02 & 1,8 & 1,4 & 72,1 \\
\hline
\end{tabular}

* Determined from the $\mathrm{N}_{2}$ desorption isotherm

Because of the derived dependence on the photocatalytic activity, the preparation of $\mathrm{ZnO}$ with a large surface area has been studied extensively [41]. The ZnO exhibits very complex and diversified morphologies, and the manipulation of a desirable structure for the rational tailoring of surface to volume ratios was largely reported. Thus, as way of example, large surface area $\mathrm{ZnO}$ photocatalysts were prepared such as spherical shape nanocrytals, flower-like, mesoporous, nanostar, nanofibers, tetrapods, nanorod arrays, porous nanopyramids, porous nanosheets, hollow spheres, nanotube arrays 
and porous films morphologies. Various preparative methods were employed such as capping agent, spray pyrolysis, the solution combustion route, the biotemplate-assisted approach, electrospinning, thermal evaporation, the solution-phase approach, the polyol solution route or chemical deposition [41]. Here we explore the influence of $\mathrm{RH}$ on the preparation of $\mathrm{ZnO}$ with increased surface area. Thus, in order to establish the surface area and porous structure of the photocatalysts, the corresponding $\mathrm{N}_{2}$ adsorption-desorption isotherms were measured.

In comparison with the bare RHA support (Figure S4), the pore structure changes considerably once $\mathrm{ZnO}$ growth covers silica support, Figure 4. The isotherms of $\mathrm{ZnO} @ \mathrm{SiO}_{2}$ composites exhibited almost the same shape, being similar to BET classification type II. These porous materials are constituted mainly by mesopores in a wide range of sizes (Figure 4 insets). Table 1 summarizes the main surface properties of the $\mathrm{ZnO@SiO} 2$ and $\mathrm{ZnO}$ samples. The pronounced hysteresis loop observed in the 0.45-0.95 $\mathrm{P} / \mathrm{P}_{0}$ range for the RHA sample (Figure S4) is almost closed. These pores are progressively blocked and covered by the $\mathrm{ZnO}$ crystals on the surface, thus explaining the significant decrease of $\mathrm{N}_{2}$ adsorption on $\mathrm{ZnO} @ \mathrm{SiO}_{2}$, as observed for other metal oxides catalysts supported on RHA[42]. The new porous structure formed by wurtzite covering the silica skeleton exhibits a surface area of around 40 $53 \mathrm{~m}^{2} \mathrm{~g}^{-1}$, being larger for samples obtained after 4 hours of calcination. In spite of the loss of surface area found from RHA to $\mathrm{ZnO} @ \mathrm{SiO}_{2}$ samples, which was four times lower, the use of a silica skeleton as a support is of high interest. Thus, without the use of RHA the isotherms show a collapsed microstructure for samples $\mathrm{Zn}-2$ and $\mathrm{Zn}-4$, exhibiting negligible surface area values lower than $5 \mathrm{~m}^{2} \mathrm{~g}^{-1}$ (Figure 4; Table I). From the results commented above, the beneficial effect of RHA as a template, which allows smaller and well dispersed ZnO particles, can be concluded.

The optical properties of the six samples were studied by a UV-visible diffuse reflectance spectroscopy (Figure S7). The acquired diffuse reflectance spectra were converted to the Kubelka-Munk function, $\left[F\left(R_{\infty}\right) h v\right]^{2}$. The band gap energies of the samples are estimated from the tangent lines in the plots of the Kubelka-Munk function vs. the energy of exciting light, as shown in Figure 5. As expected, as $\mathrm{SiO}_{2}$ is as a good insulator material (8 eV; band gap energy) [43], significant changes were not observed 
for the composites. The estimated band-gap values were in line with those reported for pure $\mathrm{ZnO} 28$, 44, 45]. Depending on the morphology and particle size of the samples (Table 1), they ranged between 3.1 and $3.2 \mathrm{eV}$. As previously reported [38] a slight decrease in band-gap values was observed with the crystallite size increase for $\mathrm{ZnO@SiO}$ samples.

\subsection{De-NO photocatalytic tests}

The photochemical ability of $\mathrm{ZnO} @ \mathrm{SiO}_{2}$ samples to abate the atmospheric concentration of nitrogen oxides gases was studied. The photochemical De-NO process proved to be efficient when $\mathrm{NO}_{\mathrm{x}}$ gases were removed from the air through their complete oxidation to nitrite/nitrate $\left(\mathrm{NO}_{2}{ }^{-} / \mathrm{NO}_{3}{ }^{-}\right)$species. This is not a simple process as it involves several intermediate species[3, 46]. Briefly, it can be summarised as follow:

$$
\begin{aligned}
& \mathrm{SC}+h v \Rightarrow \mathrm{e}^{-}+\mathrm{h}^{+} \\
& \mathrm{H} \mathrm{O}+\mathrm{h}^{+} \Rightarrow \mathrm{H}^{+}+\mathrm{OH} \\
& \mathrm{NO}+2 \mathrm{OH} \bullet \Rightarrow \mathrm{NO}_{2}+\mathrm{H}_{2} \mathrm{O} \\
& \mathrm{NO}_{2}+\mathrm{OH} \bullet \Rightarrow \mathrm{NO}_{3}^{-}+\mathrm{H}^{+} \\
& \mathrm{NO}^{+} \mathrm{NO}_{2}+\mathrm{H}_{2} \mathrm{O} \Rightarrow 2 \mathrm{HNO}_{2} \\
& \mathrm{O}_{2}+\mathrm{e}^{-} \Rightarrow \cdot \mathrm{O}_{2}^{-} \\
& \mathrm{NO}_{x}+\cdot \mathrm{O}_{2}^{-} \Rightarrow \mathrm{NO}_{3}^{-}
\end{aligned}
$$

Therefore, when sunlight shines on $\mathrm{ZnO}$ nanoparticles (semiconductor, SC) the electron in the valence band (VB) acquires the necessary energy to migrate to the conduction band (CB), (reaction 1). The pairs of mobile charges $\left(e^{-}\right.$and $\left.h^{+}\right)$that reach the surface of the semiconductor particles react with the adsorbed water and oxygen molecules $(2,6)$. Thus, the formation of reactive oxygen species (ROS) - as previously reported for $\mathrm{ZnO}$ systems $[25,26]-$ and the 
progressive oxidation of nitrogen oxide gases is initiated $(3,4,5,7)[24-26,28]$. During this process, the presence of the intermediate $\mathrm{NO}_{2}$ gas must be reduced as much as possible (3) because $\mathrm{NO}_{2}$ is far more dangerous than NO [47]. Figure 6 shows the evolution of the nitrogen oxide concentration profiles recorded for the $\mathrm{ZnO} @ \mathrm{SiO}_{2}$ samples as a function of light irradiation time. In the absence of light irradiation, in the first ten minutes of the test, the concentration of gases stayed constant confirming that neither NO gas adsorption nor any reaction on the $\mathrm{ZnO}$ particle surface occurred.

The photochemical oxidation (PCO) process began on the $\mathrm{ZnO}$ active sites once the lamp was switched on, as inferred from the sudden decrease observed for NO concentration. This PCO process was kept constant during the $30 \mathrm{~min}$ of light irradiation and stopped when the light was turned off, then the NO concentration returned to its initial value. Following this experiment, the decrease in NO concentration values measured during the light irradiation period was related to the amount of removed NO. For comparison purposes, the commercial Aeroxide ${ }^{\circledR} \mathrm{TiO}_{2} \mathrm{P}_{25}$ (Evonik) was also studied, a material broadly used worldwide as a reference in photocatalysis. In fact, this material is quite similar to the studied samples in reference to band-gap energy, crystal size and surface area (3.18 eV ; 23-44 nm; $\left.48.6 \mathrm{~m}^{2} \mathrm{~g}^{-1}\right)$ [48].

As expected, the NO conversion value was related to the surface area exhibited by the samples, around $75 \%$ for $\mathrm{ZnO@} \mathrm{SiO}_{2}$ samples and $\mathrm{TiO}_{2} \mathrm{P} 25$, and decreasing around $50 \%$ for pure ZnO samples, Figure 6a and Figure 7. As previously mentioned, it is worth remarking on the subsequent appearance of the highly toxic $\mathrm{NO}_{2}$ gas whose amount differs between samples. As is known for other modified titania photocatalysts, and different benchmark $\mathrm{TiO}_{2}$ samples, the emission of $\mathrm{NO}_{2}$ increases continuously under light irradiation in the case of the $\mathrm{TiO}_{2}-\mathrm{P} 25$ sample, Figure $6 \mathrm{~b}$ [48]. Thus, the highest slope observed for $\mathrm{TiO}_{2}-\mathrm{P} 25$ would indicate that the theoretical full oxidation of NO towards nitrites/nitrates lowers with the irradiation time, thus explaining the noticeably increased amount of $\mathrm{NO}_{2}$ molecules released during the experiment. This emission was somewhat inhibited in pure $\mathrm{ZnO}$ samples. However, it is remarkable that in $\mathrm{ZnO} @ \mathrm{SiO}_{2}$ samples the 
amount of $\mathrm{NO}_{2}$ concentration measured is negligible. By considering a sustainable process, the photocatalytic De- $\mathrm{NO}_{x}$ process must address not only the highest $\mathrm{NO}$ conversion values, but also the aim of achieving the highest De-NOx selectivity. The selectivity system parameter, $S$, expresses the ratio of degraded NO fully converted into harmless nitrite/nitrate rather than into toxic nitrogen dioxide, being determined according to the equation:

$$
S(\%)=\frac{\left([\mathrm{NOx}]_{\text {in }}-[\mathrm{NOx}]_{\text {out }}\right) /[\mathrm{NOx}]_{\text {in }}}{\left([\mathrm{NO}]_{\text {in }}-[\mathrm{NO}]_{\text {out }}\right) /[\mathrm{NO}]_{\text {in }}} \times 100
$$

Therefore, the highest $\mathrm{S}$ values mean the highest amount of nitrogen oxides removed from air. For a better comprehension of the results obtained, Figure 7 shows the conversion/emission nitrogen oxide values together with the photocatalytic $\mathrm{NO}_{x}$ abatement selectivity $(S)$, in the case of $\mathrm{ZnO@SiO}$ and should be compared with those obtained for common photocatalysts: $\mathrm{ZnO}$ and $\mathrm{TiO}_{2}-\mathrm{P} 25$ samples. The outstanding results with $\mathrm{S}$ values above $90 \%$ measured for $\mathrm{ZnO} @ \mathrm{SiO}_{2}$ samples, allowed a high amount of the whole $\mathrm{NO}_{\mathrm{x}}$ gases, around $70 \%$, to be removed. To our knowledge, these high selectivity values are scarcely reported and only for some $\mathrm{TiO}_{2}$ advanced photocatalysts[11, 13, 49-52]. In fact, due to its poor selectivity, the $\mathrm{NO}_{x}$ removal observed for $\mathrm{TiO}_{2} \mathrm{P} 25$ is limited to $35 \%$. In agreement with our findings, low $\mathrm{NO}_{2}$ release was reported for a $\mathrm{ZnO}$ thin film De- $\mathrm{NO}_{x}$ photocatalyst[23] associated with the sensitivity of this oxide to $\mathrm{NO}_{2}$ gas[53]. On the other hand, $\mathrm{S}$ values of $\mathrm{ZnO} @ \mathrm{SiO}_{2}$ samples are higher than those of $\mathrm{ZnO}$ (samples $\mathrm{Zn}-2$ and $\mathrm{Zn}-4$ ). The influence of the $\mathrm{SiO}_{2}$ support on the ZnO crystalline growth allows microstructures with higher surface area and pore volume to be obtained, making the accessibility of reactant molecules to the active sites easier and therefore, facilitating the oxidation of $\mathrm{NO}$ and $\mathrm{NO}_{2}$ molecules. In this sense, the best performance for the $\mathrm{NO} \rightarrow \mathrm{HNO}_{2} \rightarrow \mathrm{NO}_{2} \rightarrow$

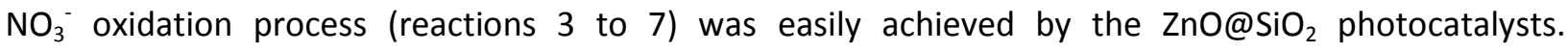
Additionally, the nitrogen oxide gases abatement performance of the last advanced De-NOx photocatalysts is compared in Table S3. From this table it is usually observed that the photocatalysts with higher NO efficiency values exhibited low De-NOx selectivity and the vice-versa. The NOx

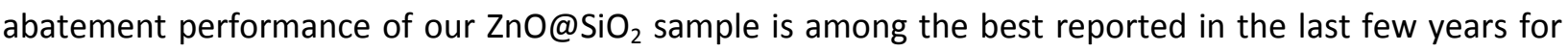


De-NOx photocatalysts as shown in Table S3, showing very high NO/NOx and S values, in similarity to BiOCl [54].

In order to confirm the mechanism proposed, which implies the selective formation and deposition of nitrite/nitrate onto the surface of the $\mathrm{ZnO} @ \mathrm{SiO}_{2}$ sample, additional evidences were obtained. FTIR measurement was used to qualitatively detect nitrogen oxide species on the surface before and after photocatalytic reactions, Figure $8 \mathrm{a}$. No bands concerning $\mathrm{N}-\mathrm{O}$ vibration modes were observed for the pristine sample. However, new absorption bands at 1258, 1327, 1375, 1518 and 1702 $\mathrm{cm}^{-1}$ appeared once the sample was subjected to the photocatalytic reaction, confirming the generation of nitrite/nitrate species during the PCO process. The bands located at 1518 and $1370 \mathrm{~cm}^{-1}$ correspond to stretching vibrations of nitrate species[55-57], whereas that at $1327 \mathrm{~cm}^{-1}$ is ascribed to nitrite ones $[57,58]$. The assignation of the band located at $1258 \mathrm{~cm}^{-1}$ could be ambiguously done for both nitrate $[57,59]$ and nitrite $[55,60]$ species. Finally, the band at $1710 \mathrm{~cm}^{-1}$ can be tentatively assigned to the adsorbed $\mathrm{NO}_{2}$ [59]. A more detailed assignment of IR bands attributed to $\mathrm{N}-\mathrm{O}$ stretching vibrations of surface nitrate $\left(\mathrm{NO}_{3}{ }^{-}\right)$and nitrite $\left(\mathrm{NO}_{2}{ }^{-}\right)$species is a difficult task, since $\mathrm{v}(\mathrm{N}-\mathrm{O})$ of different $\mathrm{NO}_{3}{ }^{-}$and $\mathrm{NO}_{2}^{-}$species fall in the same $1700-1000 \mathrm{~cm}^{-1}$ interval and their IR bands are strongly overlapped [55].

On the other hand, to shed light on differences found in De-NOx selectivity values, new evidence was obtained from preliminary $\mathrm{NO}_{2}$ adsorption studies carried out on $\mathrm{ZnO} @ \mathrm{SiO}_{2}, \mathrm{ZnO}$ and $\mathrm{TiO}_{2}-\mathrm{P} 25$ samples. Thus, a mixture of air/ $\mathrm{NO}_{2}$ was sent to the reactor with a $\mathrm{NO}_{2}$ concentration around $150 \mathrm{ppb}$, obtained by mixing synthetic air and pure $\mathrm{NO}_{2}$ (flow rate of $0.30 \mathrm{~L} \mathrm{~min}{ }^{-1} ;$ R.H. at $50 \pm 5$ ). In the absence of light irradiation, $\mathrm{NO}_{2}$ gas was passed over the samples and substantial differences were observed in the evolution of the concentration profile with time, Figure $8 \mathrm{~b}$. The $\mathrm{NO}_{2}$ concentration profile for $\mathrm{TiO}_{2}-$ P25 is similar to that of a blank test (without the presence of a catalyst). In both cases, the $\mathrm{NO}_{2}$ concentration remained constant at the initial inlet value during the time of the experiment, and therefore, there was no interaction between the gas and the catalyst or chamber surface. However, in the case of zinc oxide samples, lower concentration values for $\mathrm{NO}_{2}$ are measured during the first 30 minutes indicating that gas molecules are probably being adsorbed on their surface. This adsorption is 
higher for the dZn@RHA-4 sample because of its larger surface area compared to that of Zn-4. As aforementioned, the high De- $\mathrm{NO}_{\mathrm{x}}$ selectivity found for $\mathrm{ZnO} @ \mathrm{SiO}_{2}$ samples would be explained based on their ability to adsorb the recently formed $\mathrm{NO}_{2}$ gas molecule (reaction 3), facilitating its oxidation to nitrate before being released into the atmosphere. In the other hand, even though $\mathrm{ZnO}$ has the same band-gap energy as $\mathrm{TiO}_{2}$-anatase $(3.2 \mathrm{eV})$, its conduction band $(\mathrm{CB})$ is situated at a slightly higher energy level, which implies an increase in the reduction ability of the $C B$ electrons to form superoxide radicals $-\mathrm{O}_{2}^{-}[61,62]$. This would also favour the oxidation of the $\mathrm{NO}_{2}$ adsorbed molecules. Therefore, it can be summarized that the higher sensitivity of $\mathrm{ZnO} @ \mathrm{SiO}_{2}$ samples to $\mathrm{NO}_{2}$ gas greatly enhances the completion of $\mathrm{NO} \rightarrow \mathrm{HNO}_{2} \rightarrow \mathrm{NO}_{2} \rightarrow \mathrm{NO}_{3}{ }^{-}$photochemical oxidation process. Thus, the amount of $\mathrm{NO}_{2}$ toxic molecules which rose into the atmosphere during the photocatalytic reaction is negligible, making the use of De-NOx photocatalysts sustainable.

Finally, the potential practical application of these photocatalysts was qualitatively characterized by the evaluation of their reusability on large experiments. Figure 9 shows the diurnal mean values of NO concentration measured at an urban roadside in a highly populated city[6]. Because of the road traffic the NO concentration increases during the daytime, rapidly after sunrise and reaching its maximum level ( $\approx 180$ ppbs) between 6.00 and 12.00 in the morning. It would seem of interest that De$\mathrm{NO}_{x}$ photocatalysts could serve to abate this main $\mathrm{NO}_{x}$ peak concentration level. In this sense, the dZn@RHA-4 sample was subjected to four consecutive NO photocatalytic removal experiments run in periods of 6 hours under similar NO concentrations. The data collected (Figure 9) suggest that most of the pollution peak is abated, around 110 ppbs of NO being removed by the photocatalytic action (from a NO inlet concentration of $150 \mathrm{ppb}$ ). The photocatalytic efficiency decreased slightly in the next three cycles, probably due to the nitrite/nitrate deposition masking the photoactive sites, thus hindering the photochemical performance, this loss of efficiency being similar to that obtained during a 24 hour light irradiation test (Figure S8). In fact, after the repeated photocatalytic test cycles, the mechanism proposed is again validated by the presence of nitrite/nitrate species in the corresponding FTIR spectra (Figure S9). Thus, after the fourth run, the sample was washed with water (filtered, collected and dried) 
in order to eliminate nitrite/nitrate species (as confirmed by FTIR, Figure S9). Even though there was a small amount of decay compared to the $4^{\text {th }}$ run (probably because the washing/drying procedure must be optimized in order to avoid particle aggregations), the efficiency exhibited in the next two runs ( $5^{\text {th }}$ and $6^{\text {th }}$ ) was similar, indicating good reusability. Moreover, the selectivity (data not shown) was maintained around $85 \%$. This qualitative study shows that $\mathrm{ZnO} @ \mathrm{SiO}_{2}$ photocatalysts would be highly useful in the abatement of the NO urban pollution. The photocatalysts were prepared by cost-effective and easily scalable methodologies. As the De-NOx performance was similar enough for the four samples studied, avoiding the use of liquid solutions and decreasing the amount of energy used during the calcination process it is the preferred method for a potential industrialization of this synthetic procedure. Thus, the production of a mZn@RHA-2 sample would be preferred in which $20 \mathrm{~g}$ are easily obtained in only 3 hours of preparation at lab scale, indicating its favourable scalability.

\section{Conclusions}

A cost-effective and easily scalable methodology was reported in the preparation of a $\mathrm{ZnO}$ photocatalyst. By using simple procedures, liquid to solid deposition or mechanical milling, homogenous zinc acetate/rice husk mixtures were obtained by calcination at $600{ }^{\circ} \mathrm{C}$ thus obtaining $\mathrm{ZnO} @ \mathrm{SiO}_{2}$ samples. The $\mathrm{ZnO}$ particles, aggregated in spheres of different sizes, grow dispersed on the silica skeleton which also acts as a template. In comparison to pure zinc oxide obtained under the same experimental conditions, the use of a silica support enables a lower particle size, $70-180 \mathrm{~nm}$, and the highest surface area, $40-53 \mathrm{~m}^{2} \mathrm{~g}^{-1}$ to be obtained. Concerning the light absorption ability, $3.1-3.2 \mathrm{eV}$ band gap was estimated for ZnO@SiO2 samples.

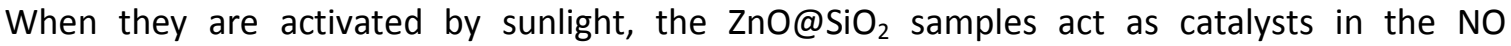
photochemical oxidation. The PCO process occurs through the $\mathrm{NO} \rightarrow \mathrm{HNO}_{2} \rightarrow \mathrm{NO}_{2} \rightarrow \mathrm{NO}_{3}^{-}$oxidation steps, as confirmed by the presence of nitrite/nitrate species on the catalyst's surface after the light induced reaction. High NO conversion values up to $75 \%$ are reached because of the high surface area exhibited by ZnO nanoparticles when grown on the silica skeleton, being limited to $50 \%$ for 
unsupported zinc oxide. It is worth mentioning the excellent De-NO selectivity values measured with $\mathrm{ZnO@SiO} 2$ photocatalyts, above $90 \%$, which allows removing approximately $70 \%$ of the $\mathrm{NO}_{\mathrm{x}}$ gases. In comparison, due to its poor selectivity, the $\mathrm{NO}_{\mathrm{x}}$ removal observed for the benchmark product $\mathrm{TiO}_{2} \mathrm{P} 25$ was limited to $35 \%$. Thus, by using $\mathrm{ZnO} @ \mathrm{SiO}_{2}$ samples the amount of $\mathrm{NO}_{2}$ gases, which rose into the atmosphere during the photocatalytic reaction, is negligible. This minimal appearance of the $\mathrm{NO}_{2}$ toxic molecules makes the use of De-NOx photocatalysts sustainable. The low emission of $\mathrm{NO}_{2}$ molecules is associated with the sensitivity of zinc oxide towards this gas. In fact, the preliminary adsorption essays indicated that $\mathrm{NO}_{2}$ gas is removed in the dark, in the presence of the $\mathrm{ZnO} @ \mathrm{SiO}_{2}$ sample. Moreover, this highly selective and sustainable photocatalyst exhibits high efficiency and recovery when operated under experimental conditions similar to $\mathrm{NO}_{\mathrm{x}}$ urban pollution periods (150 ppb NO; 6 hours), thus being proposed as a potential photocatalyst for air remediation. Because of their outstanding results of selectivity, further study will be addressed in the near future to ensure that the photocatalytic process works even more effectively. In this sense, metal doping would be an interesting strategy (preventing the recombination of the charge carriers), as we know that doped $\mathrm{ZnO}$ surpasses the photocatalytic efficiency of an un-doped one [63].

\section{Acknowledgements}

The Spanish (MINECO; MAT2017-88284-P) and Junta de Andalucía governments (PAI Groups FQM-214 and FQM-175) financed this work. Adrián Pastor acknowledges a grant from the Ministerio de Educación, Cultura y Deporte (FPU16/05041) to research at the University of Córdoba (Spain).

\section{Appendix A. Supplementary data}

Supplementary Information (SI) accompanying this paper includes more information about: the characterization of rice husk ash (SEM, XRD, Chemical analysis, $\mathrm{N}_{2}$ absorption isotherms); Experimental; Thermogravimetric analysis; Particle size distribution. 


\section{References}

[1] R. Vinu, G. Madras, Environmental remediation by photocatalysis, J. Indian Inst. Sci. 90 (2012) 189230.

[2] X. Li, J. Yu, M. Jaroniec, Hierarchical photocatalysts, Chem. Soc. Rev. 45 (2016) 2603-2636.

[3] J. Balbuena, M. Cruz-Yusta, L. Sánchez, Nanomaterials to Combat $\mathrm{NO}_{x}$ Pollution, J. Nanosci. Nanotechnol. 15 (2015) 6373-6385.

[4] M.W. Frampton, I.A. Greaves, $\mathrm{NO}_{\mathrm{x}}-\mathrm{NO}_{\mathrm{x}}$ : Who's There?, Am. J. Respir. Crit. Care. Med. 179 (2009) 1077-1078.

[5] Y. Chen, J. Borken-Kleefeld, $\mathrm{NO}_{\mathrm{x}}$ Emissions from Diesel Passenger Cars Worsen with Age, Environ. Sci. Technol. 50 (2016) 3327-3332.

[6] S.K. Pandey, K.-H. Kim, S.-Y. Chung, S.J. Cho, M.Y. Kim, Z.-H. Shon, Long-term study of $\mathrm{NO}_{\mathrm{x}}$ behavior at urban roadside and background locations in Seoul, Korea, Atmos. Environ. 42 (2008) 607-622.

[7] H. Nie, M. Ou, Q. Zhong, S. Zhang, L. Yu, Efficient visible-light photocatalytic oxidation of gaseous NO with graphitic carbon nitride $\left(\mathrm{g}-\mathrm{C}_{3} \mathrm{~N}_{4}\right)$ activated by the alkaline hydrothermal treatment and mechanism analysis, J. Hazard. Mater. 300 (2015) 598-606.

[8] J. Chen, C.-s. Poon, Photocatalytic construction and building materials: From fundamentals to applications, Build. Environ. 44 (2009) 1899-1906.

[9] S. Karapati, T. Giannakopoulou, N. Todorova, N. Boukos, I. Papailias, D. Dimotikali, C. Trapalis, Novel 'Pickering' modified $\mathrm{TiO}_{2}$ photocatalysts with high De-NOx efficiency, Catal. Today 287 (2017) 45-51.

[10] T. Giannakopoulou, I. Papailias, N. Todorova, N. Boukos, Y. Liu, J. Yu, C. Trapalis, Tailoring the energy band gap and edges' potentials of $\mathrm{g}-\mathrm{C}_{3} \mathrm{~N}_{4} / \mathrm{TiO}_{2}$ composite photocatalysts for $\mathrm{NO}_{\mathrm{x}}$ removal, Chem. Eng. J. 310 (2017) 571-580. 
[11] B. Tan, X. Zhang, Y. Li, H. Chen, X. Ye, Y. Wang, J. Ye, Anatase TiO ${ }_{2}$ Mesocrystals: Green Synthesis, In Situ Conversion to Porous Single Crystals, and Self-Doping $\mathrm{Ti}^{3+}$ for Enhanced Visible Light Driven Photocatalytic Removal of NO, Chem. Eur. J. 23 (2017) 5478-5487.

[12] N.C.T. Martins, J. Ângelo, A.V. Girão, T. Trindade, L. Andrade, A. Mendes, N-doped carbon quantum dots $/ \mathrm{TiO}_{2}$ composite with improved photocatalytic activity, Appl. Catal. B: Environ. 193 (2016) 67-74.

[13] J. Balbuena, J.M. Calatayud, M. Cruz-Yusta, P. Pardo, F. Martin, J. Alarcon, L. Sanchez, Mesocrystalline anatase nanoparticles synthesized using a simple hydrothermal approach with enhanced light harvesting for gas-phase reaction, Dalton Trans. (2018).

[14] E.C. Agency, ANNEX 2 - Comments and response to comments on CLH proposal on titanium dioxide, 2017.

[15] J. Balbuena, M. Cruz-Yusta, A. Pastor, L. Sánchez, $\alpha-\mathrm{Fe}_{2} \mathrm{O}_{3} / \mathrm{SiO}_{2}$ composites for the enhanced photocatalytic NO oxidation, J. Alloys Compd. 735 (2018) 1553-1561.

[16] J. Luo, G. Dong, Y. Zhu, Z. Yang, C. Wang, Switching of semiconducting behavior from n-type to ptype induced high photocatalytic NO removal activity in $\mathrm{g}^{-} \mathrm{C}_{3} \mathrm{~N}_{4}$, Appl. Catal. B: Environ. 214 (2017) 4656.

[17] F. Dong, T. Xiong, Z. Zhao, Y. Sun, M. Fu, Ammonia induced formation of $\mathrm{N}$-doped $(\mathrm{BiO})_{2} \mathrm{CO}_{3}$ hierarchical microspheres: the effect of hydrothermal temperature on the morphology and photocatalytic activity, CrystEngComm 15 (2013) 10522-10532.

[18] Z. Ai, W. Ho, S. Lee, L. Zhang, Efficient Photocatalytic Removal of NO in Indoor Air with Hierarchical Bismuth Oxybromide Nanoplate Microspheres under Visible Light, Environ. Sci. Technol. 43 (2009) 41434150.

[19] Y. Gao, Y. Huang, Y. Li, Q. Zhang, J.-j. Cao, W. Ho, S.C. Lee, Plasmonic Bi/ZnWO ${ }_{4}$ Microspheres with Improved Photocatalytic Activity on NO Removal under Visible Light, ACS Sustain. Chem. Eng. 4 (2016) 6912-6920. 
[20] S. Zhu, L. Lu, Z. Zhao, T. Wang, X. Liu, H. Zhang, F. Dong, Y. Zhang, Mesoporous Ni-Doped $\delta-\mathrm{Bi}_{2} \mathrm{O}_{3}$ Microspheres for Enhanced Solar-Driven Photocatalysis: A Combined Experimental and Theoretical Investigation, J. Phys. Chem. C 121 (2017) 9394-9401.

[21] K.B. Kim, Y.W. Kim, S.K. Lim, T.H. Roh, D.Y. Bang, S.M. Choi, D.S. Lim, Y.J. Kim, S.H. Baek, M.K. Kim, H.S. Seo, M.H. Kim, H.S. Kim, J.Y. Lee, S. Kacew, B.-M. Lee, Risk assessment of zinc oxide, a cosmetic ingredient used as a UV filter of sunscreens, J. Toxicol. Environ. Health B 20 (2017) 155-182.

[22] C.C. Pei, W.W.-F. Leung, Enhanced photocatalytic activity of electrospun $\mathrm{TiO}_{2} / \mathrm{ZnO}$ nanofibers with optimal anatase/rutile ratio, Catal. Commun. 37 (2013) 100-104.

[23] N. Todorova, T. Giannakopoulou, K. Pomoni, J. Yu, T. Vaimakis, C. Trapalis, Photocatalytic NOx oxidation over modified $\mathrm{ZnO} / \mathrm{TiO}_{2}$ thin films, Catal. Today 252 (2015) 41-46.

[24] E. Kowsari, S. Abdpour, Investigation performance of rod-like $\mathrm{ZnO} / \mathrm{CdO}$ composites, synthesized in ionic liquid medium as photocatalytic for degradation of air pollutants $\left(\mathrm{SO}_{2}\right.$ and $\left.\mathrm{NO}_{\mathrm{x}}\right)$, Optik $127(2016)$ 11567-11576.

[25] E. Kowsari, S. Abdpour, In-situ functionalization of mesoporous hexagonal ZnO synthesized in task specific ionic liquid as a photocatalyst for elimination of $\mathrm{SO}_{2}, \mathrm{NO}_{x}$, and $\mathrm{CO}$, J. Solid State Chem. 256 (2017) 141-150.

[26] E. Kowsari, B. Bazri, Synthesis of rose-like ZnO hierarchical nanostructures in the presence of ionic liquid/ $\mathrm{Mg}^{2+}$ for air purification and their shape-dependent photodegradation of $\mathrm{SO}_{2}, \mathrm{NO}_{x}$, and $\mathrm{CO}$, Appl. Catal. A: Gen. 475 (2014) 325-334.

[27] Y. Huang, C. Guo, L. Huang, Q. Dong, S. Yin, T. Sato, Photocatalytic oxidation of $\mathrm{NO}_{\mathrm{x}}$ gases using $\mathrm{ZnO}$ with superstructure by a low temperature soft solution process, Int. J. Nanotechnol. 10 (2012) 30-37. [28] Y. Wei, Y. Huang, J. Wu, M. Wang, C. Guo, D. Qiang, S. Yin, T. Sato, Synthesis of hierarchically structured $\mathrm{ZnO}$ spheres by facile methods and their photocatalytic De- $\mathrm{NO}_{\mathrm{x}}$ properties, J. Hazard. Mater. 248-249 (2013) 202-210. 
[29] F. Adam, J.N. Appaturi, R. Thankappan, M.A.M. Nawi, Silica-tin nanotubes prepared from rice husk ash by sol-gel method: Characterization and its photocatalytic activity, Appl. Surf. Sci. 257 (2010) 811 816.

[30] Y. Li, J.Y. Lan, J. Liu, J. Yu, Z. Luo, W. Wang, L. Sun, Synthesis of Gold Nanoparticles on Rice Husk Silica for Catalysis Applications, Ind. Eng. Chem. Res. 54 (2015) 5656-5663.

[31] A. Jaroenworaluck, N. Pijarn, N. Kosachan, R. Stevens, Nanocomposite $\mathrm{TiO}_{2}-\mathrm{SiO}_{2}$ gel for UV absorption, Chem. Eng. J. 181-182 (2012) 45-55.

[32] H. Chen, L. Zhao, Y. Xiang, Y. He, G. Song, X. Wang, F. Liang, A novel Zn- $\mathrm{TiO}_{2} / \mathrm{C} @ \mathrm{SiO}_{2}$ nanoporous material on rice husk for photocatalytic applications under visible light, Desalination and Water Treatment 57 (2016) 9660-9670.

[33] C. Tian, Q. Zhang, A. Wu, M. Jiang, Z. Liang, B. Jiang, H. Fu, Cost-effective large-scale synthesis of ZnO photocatalyst with excellent performance for dye photodegradation, Chem. Commun. 48 (2012) 2858-2860.

[34] P. Sujaridworakun, S. Jinawath, W. Panpa, A. Nakajima, M. Yoshimura, Hydrothermal Synthesis of TiO2/SiO2 Hybrid Photocatalyst from Rice Husk Ash, Key Eng. Mater. 352 (2007) 281-285.

[35] ISO, Fine ceramics (advanced ceramics, advanced technical ceramics) -- Test method for airpurification performance of semiconducting photocatalytic materials -- Part 1: Removal of nitric oxide, in: ISO (Ed.), International Organization for Standardization, 2007.

[36] F. Rodriguez-Rivas, A. Pastor, C. Barriga, M. Cruz-Yusta, L. Sánchez, I. Pavlovic, Zn-Al layered double hydroxides as efficient photocatalysts for NOx abatement, Chem. Eng. J. 346 (2018) 151-158.

[37] M.E. Monge, B. D'Anna, C. George, Nitrogen dioxide removal and nitrous acid formation on titanium oxide surfaces -an air quality remediation process?, Phys. Chem. Chem. Phys. 12 (2010) 89918998.

[38] T.S.T. da Silva Gelson, T.G. Carvalho Kele, F. Lopes Osmando, S. Gomes Eliziana, R. Malagutti Andréa, R. Mastelaro Valmor, C. Ribeiro, A.J.L. Mourão Henrique, Synthesis of ZnO Nanoparticles 
Assisted by $\mathrm{N}$ Sources and their Application in the Photodegradation of Organic Contaminants, ChemCatChem 9 (2017) 3795-3804.

[39] L. Shi, P. Zhu, R. Yang, X. Zhang, J. Yao, F. Chen, X. Gao, P. Ai, N. Tsubaki, Functional rice husk as reductant and support to prepare as-burnt $\mathrm{Cu}$-ZnO based catalysts applied in low-temperature methanol synthesis, Catal. Commun. 89 (2017) 1-3.

[40] L.A. O'Dell, S.L.P. Savin, A.V. Chadwick, M.E. Smith, Structural studies of silica- and alumina-pinned nanocrystalline $\mathrm{SnO}_{2}$, Nanotechnology 16 (2005) 1836.

[41] S.G. Kumar, K.S.R.K. Rao, Zinc oxide based photocatalysis: tailoring surface-bulk structure and related interfacial charge carrier dynamics for better environmental applications, RSC Adv. 5 (2015) 3306-3351.

[42] A.E. Ahmed, F. Adam, The benzylation of benzene using aluminium, gallium and iron incorporated silica from rice husk ash, Microporous Mesoporous Mater. 118 (2009) 35-43.

[43] S. Vives, C. Meunier, Optical properties of copper modified sol-gel $\mathrm{SiO}_{2}$ thin films, Mater. Lett. 91 (2013) 165-169.

[44] S. Kaviya, E. Prasad, Eco-friendly synthesis of $\mathrm{ZnO}$ nanopencils in aqueous medium: a study of photocatalytic degradation of methylene blue under direct sunlight, RSC Adv. 6 (2016) 33821-33827.

[45] A.K. Zak, M.E. Abrishami, W.H.A. Majid, R. Yousefi, S.M. Hosseini, Effects of annealing temperature on some structural and optical properties of $\mathrm{ZnO}$ nanoparticles prepared by a modified sol-gel combustion method, Ceram. Int. 37 (2011) 393-398.

[46] S. Devahasdin, C. Fan Jr, K. Li, D.H. Chen, $\mathrm{TiO}_{2}$ photocatalytic oxidation of nitric oxide: transient behavior and reaction kinetics, J. Photochem. Photobiol. A 156 (2003) 161-170.

[47] R.J. Lewis, N.I. Sax, Sax's Dangerous Properties of Industrial Materials, 12th ed., Van Nostrand Reinhold, New York, 2012.

[48] M.J. Hernández Rodríguez, E. Pulido Melián, O. González Díaz, J. Araña, M. Macías, A. González Orive, J.M. Doña Rodríguez, Comparison of supported $\mathrm{TiO}_{2}$ catalysts in the photocatalytic degradation of NO , J. Mol. Catal. A: Chem. 413 (2016) 56-66. 
[49] J. Ma, H. Wu, Y. Liu, H. He, Photocatalytic Removal of $\mathrm{NO}_{x}$ over Visible Light Responsive OxygenDeficient $\mathrm{TiO}_{2}$, J. Phys. Chem. C 118 (2014) 7434-7441.

[50] N. Todorova, T. Giannakopoulou, S. Karapati, D. Petridis, T. Vaimakis, C. Trapalis, Composite $\mathrm{TiO}_{2}$ /clays materials for photocatalytic $\mathrm{NO}_{x}$ oxidation, Appl. Surf. Sci. 319 (2014) 113-120.

[51] A. Trapalis, N. Todorova, T. Giannakopoulou, N. Boukos, T. Speliotis, D. Dimotikali, J. Yu, $\mathrm{TiO}_{2}$ /graphene composite photocatalysts for $\mathrm{NO}_{\mathrm{X}}$ removal: A comparison of surfactant-stabilized graphene and reduced graphene oxide, Appl. Catal. B: Environ. 180 (2016) 637-647.

[52] A.V. Katsanaki, A.G. Kontos, T. Maggos, M. Pelaez, V. Likodimos, E.A. Pavlatou, D.D. Dionysiou, P. Falaras, Photocatalytic oxidation of nitrogen oxides on N-F-doped titania thin films, Appl. Catal. B: Environ. 140-141 (2013) 619-625.

[53] S. Öztürk, N. Kılınç, N. Taşaltin, Z.Z. Öztürk, A comparative study on the $\mathrm{NO}_{2}$ gas sensing properties of ZnO thin films, nanowires and nanorods, Thin Solid Films 520 (2011) 932-938.

[54] H. Li, H. Shang, X. Cao, Z. Yang, Z. Ai, L. Zhang, Oxygen Vacancies Mediated Complete Visible Light NO Oxidation via Side-On Bridging Superoxide Radicals, Environ. Sci. Technol. 52 (2018) 8659-8665.

[55] R.V. Mikhaylov, A.A. Lisachenko, B.N. Shelimov, V.B. Kazansky, G. Martra, S. Coluccia, FTIR and TPD Study of the Room Temperature Interaction of a NO-Oxygen Mixture and of $\mathrm{NO}_{2}$ with Titanium Dioxide, J. Phys. Chem. C 117 (2013) 10345-10352.

[56] R. Sugrañez, J. Balbuena, M. Cruz-Yusta, F. Martín, J. Morales, L. Sánchez, Efficient behaviour of hematite towards the photocatalytic degradation of $\mathrm{NO}_{x}$ gases, Appl. Catal. B: Environ. 165 (2015) 529536.

[57] K.I. Hadjiivanov, Identification of neutral and charged $\mathrm{N}_{X} \mathrm{O}_{Y}$ surface species by IR spectroscopy, Catal. Rev. Sci. Eng. 42 (2000) 71-144.

[58] J. Sá, J.A. Anderson, FTIR study of aqueous nitrate reduction over $\mathrm{Pd} / \mathrm{TiO}_{2}$, Appl. Catal. B: Environ. 77 (2008) 409-417.

[59] B. Zhao, R. Ran, X. Wu, D. Weng, X. Wu, C. Huang, Comparative study of $\mathrm{Mn} / \mathrm{TiO}_{2}$ and $\mathrm{Mn} / \mathrm{ZrO}_{2}$ catalysts for NO oxidation, Catal. Commun. 56 (2014) 36-40. 
[60] Y. Duan, M. Zhang, L. Wang, F. Wang, L. Yang, X. Li, C. Wang, Plasmonic Ag-TiO ${ }_{2-x}$ nanocomposites for the photocatalytic removal of NO under visible light with high selectivity: The role of oxygen vacancies, Appl. Catal. B: Environ. 204 (2017) 67-77.

[61] A.L. Linsebigler, G. Lu, J.T. Yates, Photocatalysis on $\mathrm{TiO}_{2}$ Surfaces: Principles, Mechanisms, and Selected Results, Chem. Rev. 95 (1995) 735-758.

[62] T. Giannakopoulou, I. Papailias, N. Todorova, N. Boukos, Y. Liu, J. Yu, C. Trapalis, Tailoring the energy band gap and edges' potentials of g-C3N4/TiO2 composite photocatalysts for NOx removal, Chem. Eng. J. 310 (2017) 571-580.

[63] K.M. Lee, C.W. Lai, K.S. Ngai, J.C. Juan, Recent developments of zinc oxide based photocatalyst in water treatment technology: a review, Water Res. 88 (2016) 428-448. 


\section{Figure Captions}

Figure 1: XRD patterns for dZn@RHA, mZn@RHA and Zn samples.

Figure 2: SEM images for dZn@RHA-2 (a, c) and dZn@RHA-4 (b, d) samples.

Figure 3: SEM images for mZn@RHA-2 (a, c), mZn@RHA-4 (b, d), Zn-2 (e) and Zn-4 (f) samples.

Figure 4: $\mathrm{N}_{2}$ adsorption-desorption isotherm and pore size distribution for dZn@RHA, Zn@RHA and Zn samples.

Figure 5: Kubelka-Munk transformed reflectance spectra for Zn@RHA (a) and Zn (b) samples.

Figure 6: Nitrogen oxides concentration profiles obtained during the photo-degradation of gaseous NO under light irradiation ondZn@RHA, mZn@RHA and Zn samples.

Figure 7: $\mathrm{NO}$ conversion (\%, blue), $\mathrm{NO}_{2}$ released (\%, orange), $\mathrm{NO}_{\mathrm{x}}$ conversion (\%, grey) and Selectivity values (\%, yellow) for dZn-RHA, mZn-RHA, $\mathrm{Zn}$ and $\mathrm{TiO}_{2}-\mathrm{P} 25$ samples.

Figure 8: (a) IR spectra obtained for dZn@RHA-4 sample before and after light irradiation. (b) $\mathrm{NO}_{2}$ concentration profiles obtained in dark condition for $\mathrm{Zn}-4$, dZn@RHA-4 and $\mathrm{TiO}_{2}$ samples. Red line marks the $\mathrm{NO}_{2}$ inlet concentration.

Figure 9: Diurnal distribution pattern of NO gas at urban roadside (grey shading) and NO concentration profile obtained for dZn@RHA-4 sample (o) at different runs during 6 hours of light irradiation (NO inlet concentration: $150 \mathrm{ppb}$ ). The sample was washed and dried after the $4^{\text {th }}$ run. 


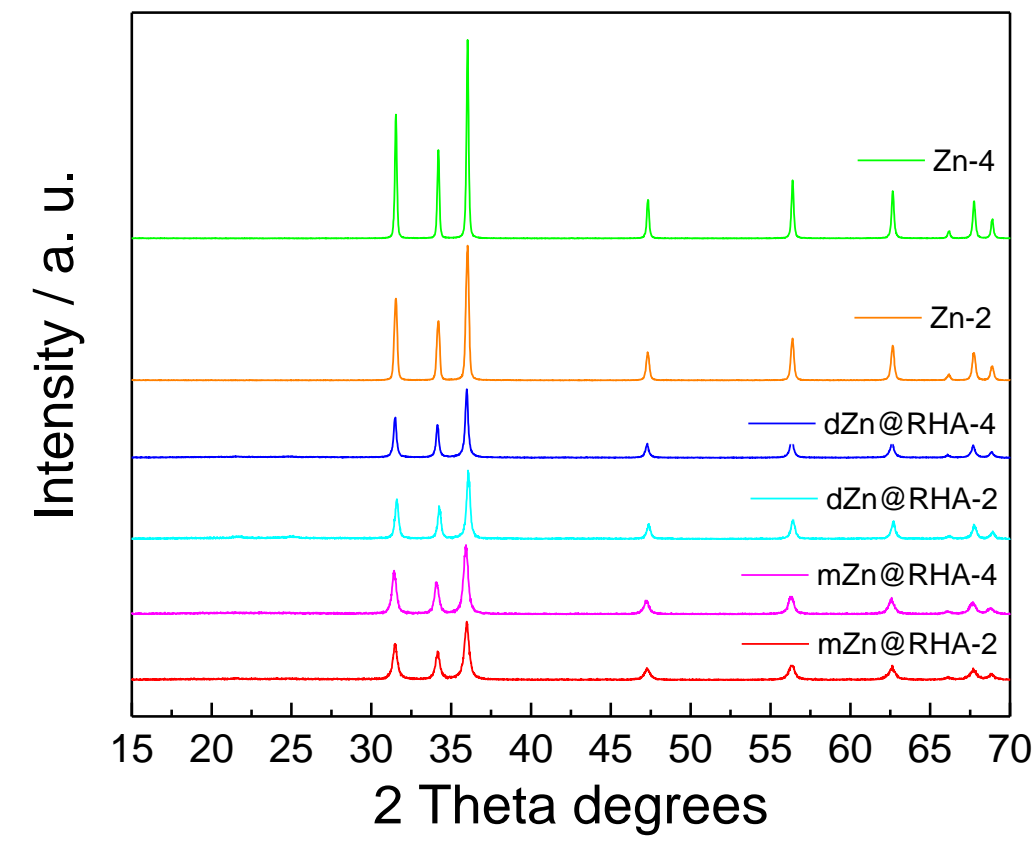



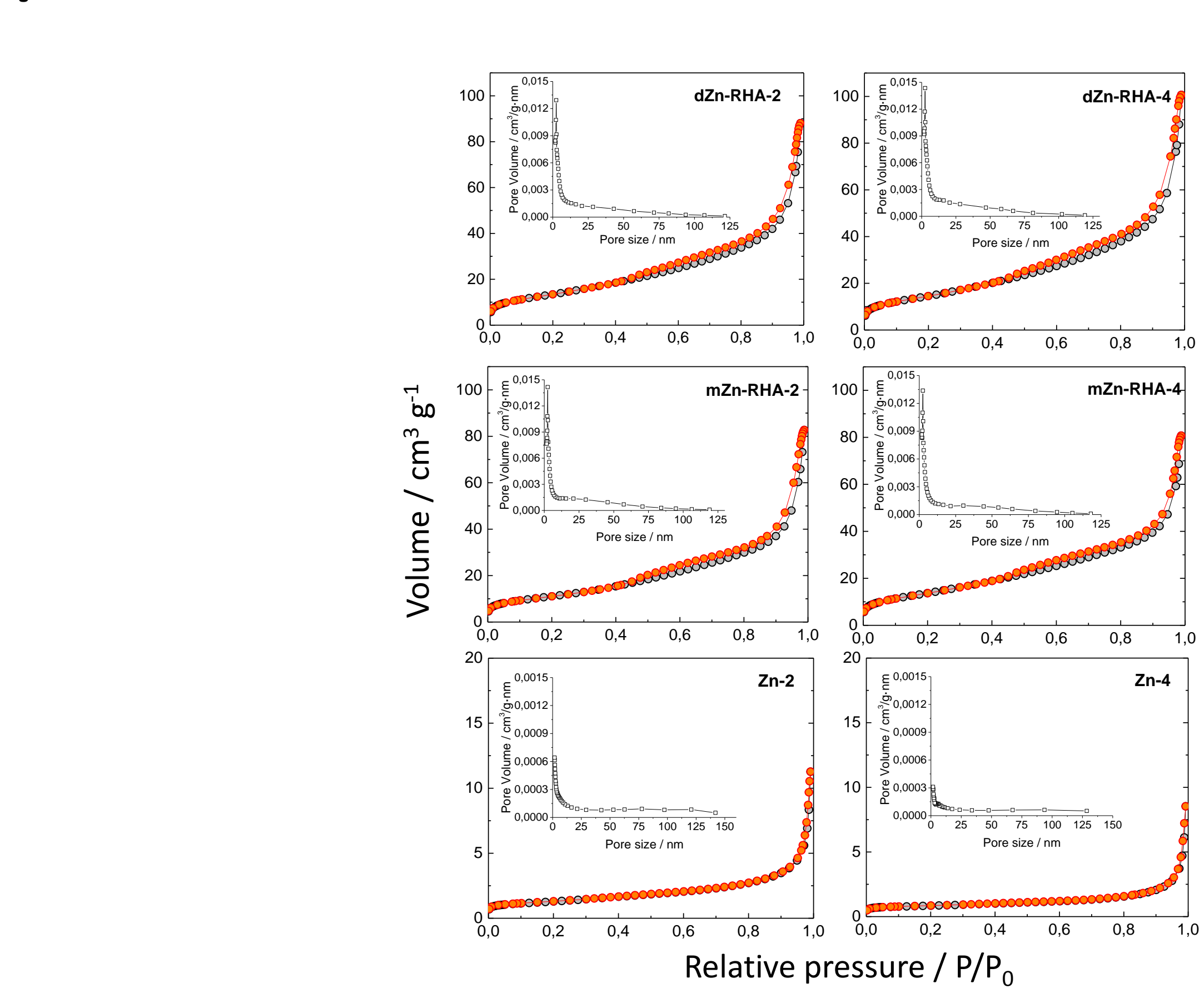

Relative pressure / $\mathrm{P} / \mathrm{P}_{0}$ 

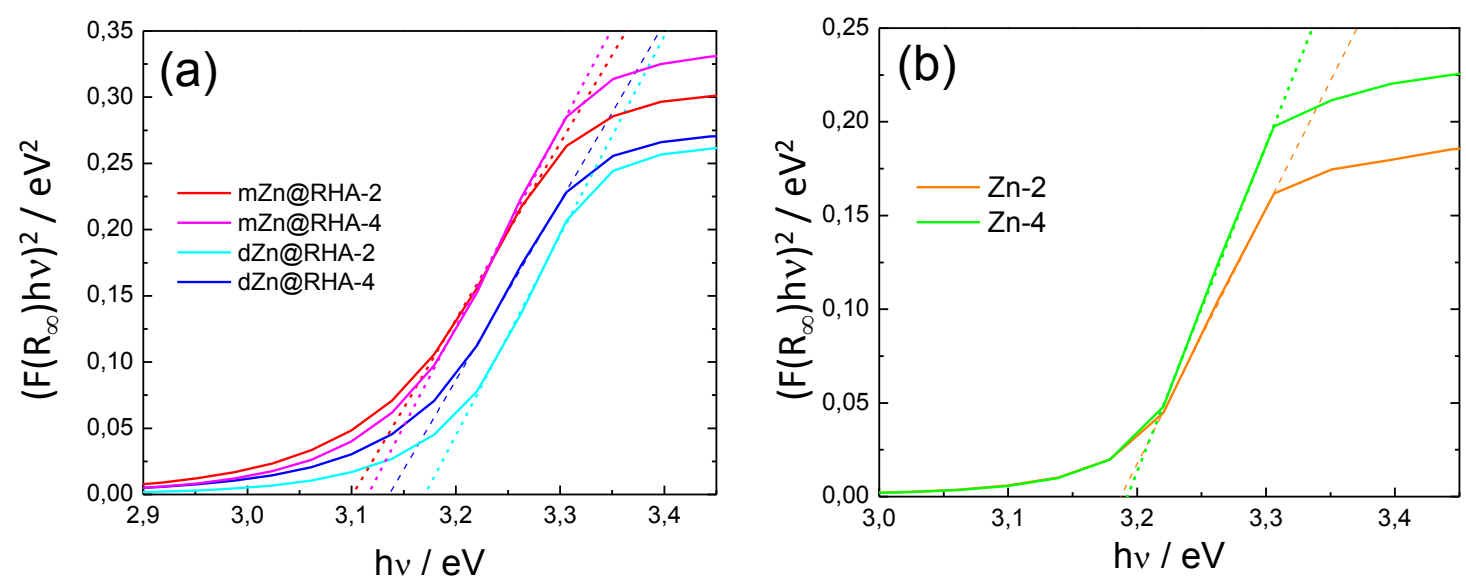


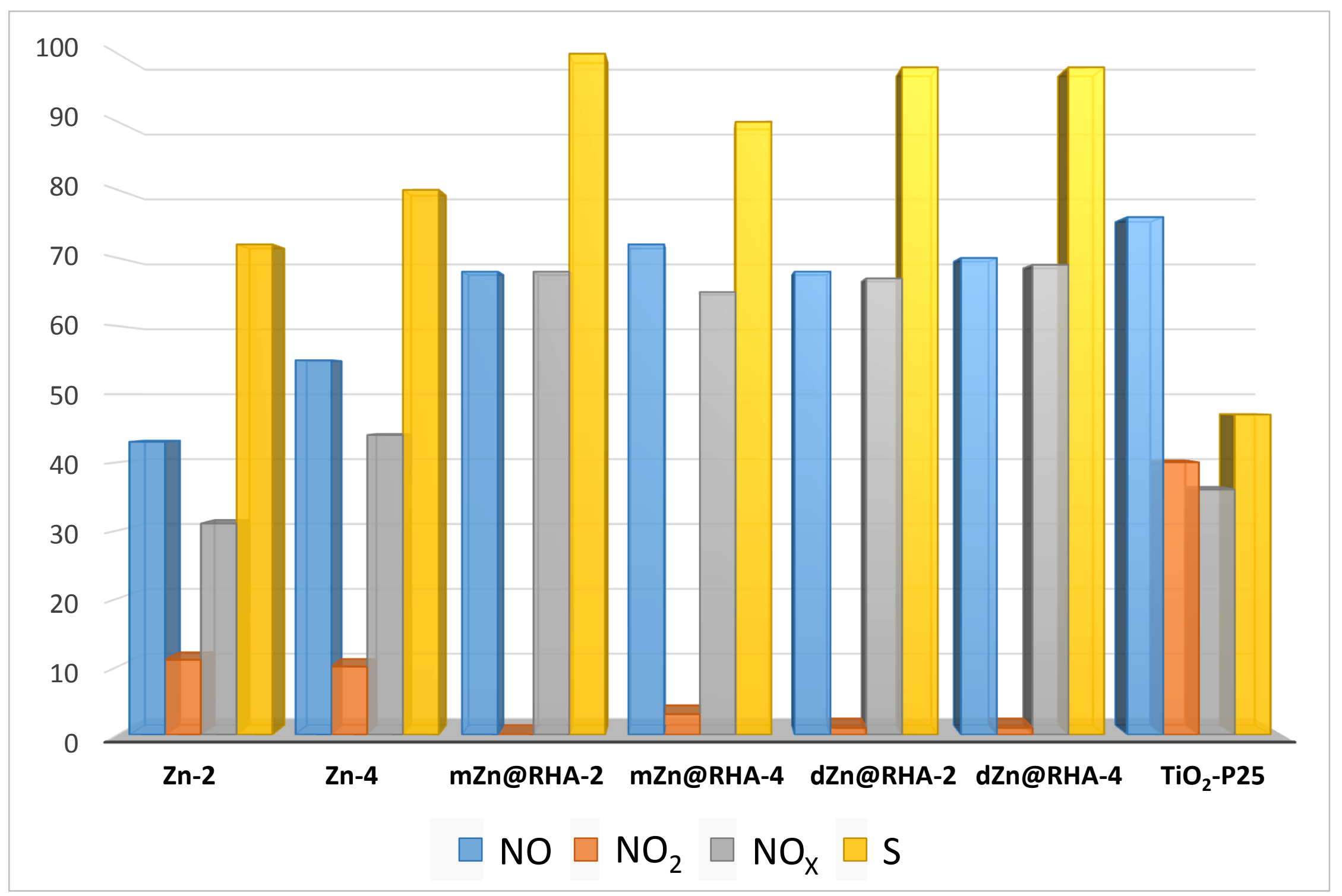



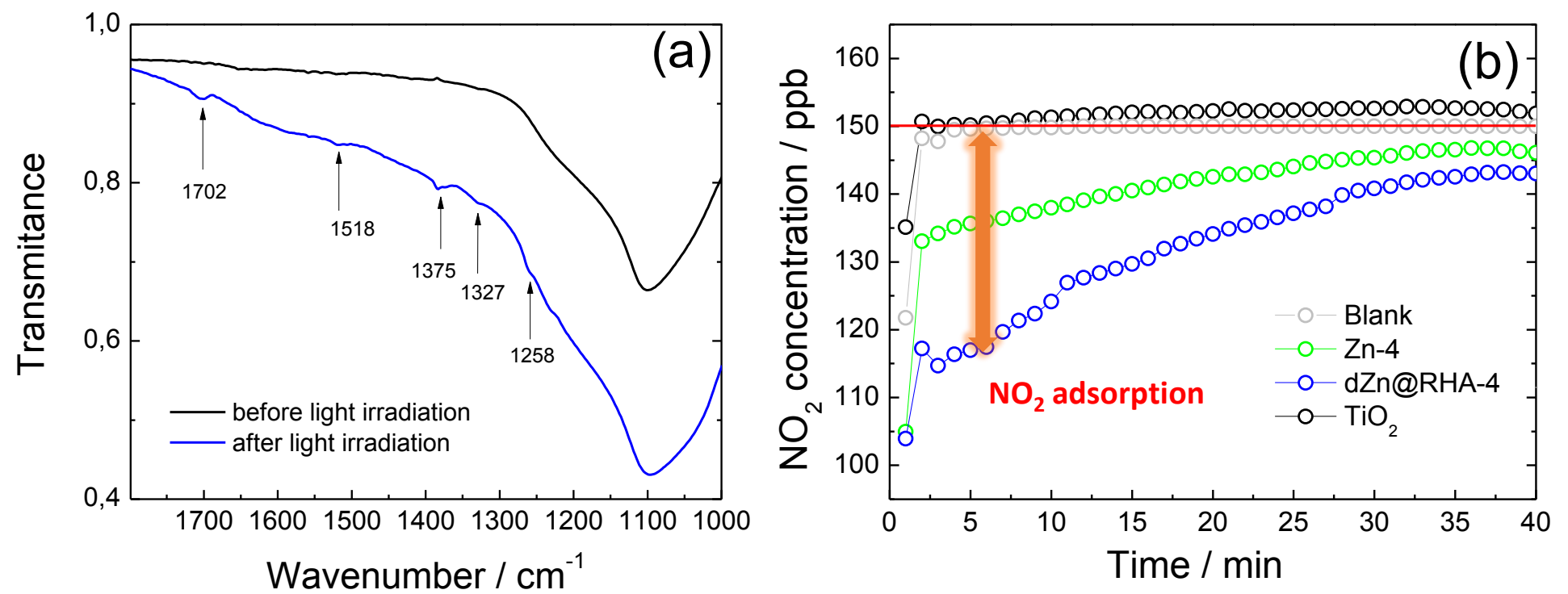


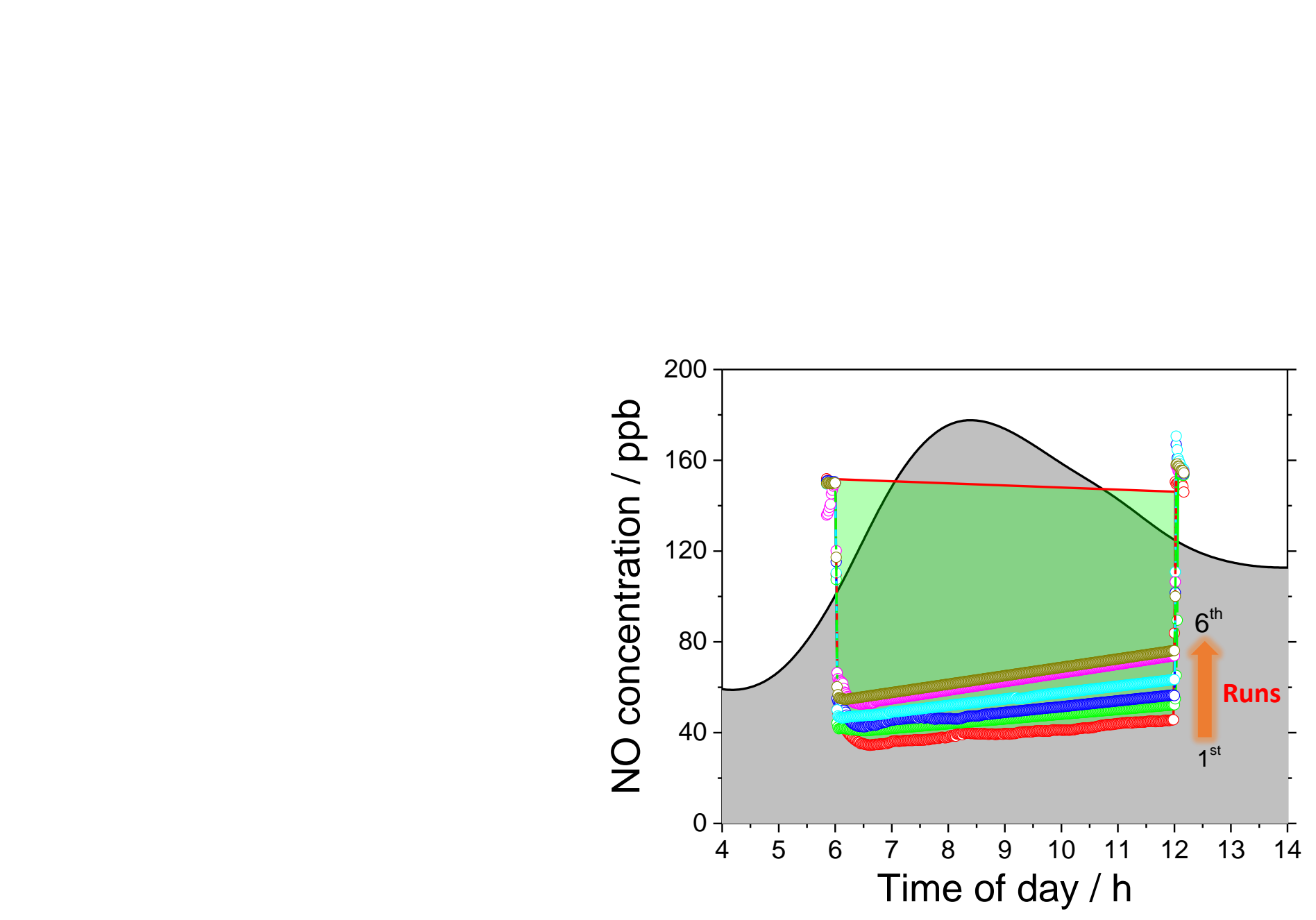

Time of day / $h$ 